\title{
Discovery of Peptidomimetic Ligands of EED as Allosteric Inhibitors of PRC2
}

\author{
Kimberly D. Barnash ${ }^{\dagger}$, Juliana The ${ }^{\ddagger}$, Jacqueline L. Norris-Drouin ${ }^{\dagger}$, Stephanie $\mathbf{H}$. \\ Cholensky $^{\dagger}$, Beau M. Worley ${ }^{\dagger}$, Fengling Li ${ }^{\ddagger}$, Jacob I. Stuckey ${ }^{\dagger}$, Peter J. Brown ${ }^{\ddagger}$, Masoud \\ Vedadi $^{\ddagger}$, Cheryl H. Arrowsmith ${ }^{\ddagger}$, Stephen V. Frye ${ }^{\star}, \dagger$, and Lindsey I. James ${ }^{*}, \dagger$ \\ tCenter for Integrative Chemical Biology and Drug Discovery, Division of Chemical Biology and \\ Medicinal Chemistry, UNC Eshelman School of Pharmacy, University of North Carolina at Chapel \\ Hill, Chapel Hill, North Carolina 27599, USA \\ ‡Structural Genomics Consortium, University of Toronto, Toronto, Ontario, M5G 1L7, Canada
}

\begin{abstract}
The function of EED within Polycomb repressive complex 2 (PRC2) is mediated by a complex network of protein-protein interactions. Allosteric activation of PRC2 by binding of methylated proteins to embryonic ectoderm development (EED) aromatic cage is essential for full catalytic activity, but details of this regulation are not fully understood. EED's recognition of the product of PRC2 activity, histone $\mathrm{H} 3$ lysine 27 trimethylation (H3K27me3), stimulates PRC2 methyltransferase activity at adjacent nucleosomes leading to $\mathrm{H} 3 \mathrm{~K} 27 \mathrm{me} 3$ propagation and, ultimately, gene repression. By coupling combinatorial chemistry and structure-based design, we optimized a low affinity methylated jumonji, AT rich interactive domain 2 (Jarid2) peptide to a smaller, more potent peptidomimetic ligand $\left(K_{d}=1.14 \pm 0.14 \mu \mathrm{M}\right)$ of the aromatic cage of EED. Our strategy illustrates the effectiveness of applying combinatorial chemistry to achieve both ligand potency and property optimization. Furthermore, the resulting ligands, UNC5114 and UNC5115, demonstrate that targeted disruption of EED's reader function can lead to allosteric inhibition of PRC2 catalytic activity.
\end{abstract}

\section{Graphical Abstract}

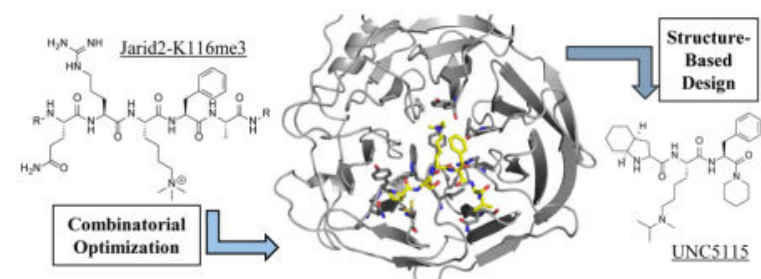

Corresponding Authors: ingerman@email.unc.edu and svfrye@email.unc.edu.

The authors declare no competing financial interest.

Supporting Information. Supporting figures, a detailed description of the chemical synthesis and characterization, and the materials and experimental methods are described in the Supporting Information. This material is available free of charge via the Internet at http://pubs.acs.org. 


\section{Keywords}

Methyl-lysine; Polycomb; one-bead-one-compound; peptidomimetic

\section{INTRODUCTION}

PRC2 is a multisubunit protein complex controlling cellular fate decisions through epigenetic transcriptional repression of key genes involved in development. The fundamental role of PRC2 deposition of the repressive chromatin mark, H3K27me3, promoted extensive characterization of the PRC2 core complex, consisting of enhancer of zeste homolog 1/2 (Ezh1/2) (the methyltransferase catalytic subunit), suppressor of zeste 12 (Suz12), and $\mathrm{EED}^{1-4}$. As a central mediator of gene repression, PRC2 functions are both diverse and essential, but the complexity of PRC2 biology has prevented the establishment of a straightforward and comprehensive model for its actions ${ }^{5-7}$. Recent efforts have led to new insights into PRC2 regulation of chromatin structure and gene repression along with indications of PRC2 misregulation in disease, particularly in cases of hematopoietic cancers 8 and pediatric glioma ${ }^{9}$. The discovery of potent, in vivo chemical probes of Ezh1/2 $2^{10-13}$ have aided in validating Ezh2 as a druggable component of PRC2, and encouragingly, Ezh2 inhibitors have since entered clinical trials ${ }^{14}$. New chemical tools to study other components of PRC2 may similarly provide a path to an improved understanding of its regulation, function, and therapeutic potential.

While a complete mechanistic understanding of PRC2 function remains elusive, several research groups have characterized the allosteric regulation of PRC2 activity facilitated by EED. Similar to many WD40 proteins, EED serves as a scaffold for protein complex assembly ${ }^{15}$. EED's indispensable role in PRC2 involves an intricate network of proteinprotein interactions with both Ezh2 and Suz12, as Ezh2's catalytic activity is entirely dependent on PRC2 core complex formation ${ }^{3-4}$. EED associates with the product of PRC2 activity, H3K27me3, and EED binding to H3K27me3 stimulates PRC2 to methylate adjacent nucleosomes leading to $\mathrm{H} 3 \mathrm{~K} 27 \mathrm{me} 3$ propagation over large genomic loci and gene repression ${ }^{16}$. EED has also been shown to interact with inhibitory histone marks (histone H1 lysine 26 trimethylation $)^{17}$, but the biological significance of this mark for EED regulation has been poorly studied.

Recently, Jarid2 trimethylated at lysine 116 (Jarid2-K116me3) was described as an EED binding partner and allosteric activator of PRC2 methyltransferase activity ${ }^{18}$. The regulation of PRC2 through EED binding to both H3K27me3 and Jarid2-K116me3 illustrates the difficulty in developing a comprehensive model for PRC2 regulation. Moreover, the methylated Jarid2 peptide demonstrates 10-fold higher affinity for EED in vitro than H3K27me3 (3.4 vs $40 \mu \mathrm{M})$.

The recently solved crystal structures of the three core components of PRC2 are noteworthy achievements, and importantly provide a clear model for the allosteric activation of Ezh2's methyltransferase activity by EED ${ }^{15,19,20}$. Engagement of the aromatic cage and top surface of EED by methylated Jarid2-K116me3 (or H3K27me3) ${ }^{15}$ stimulates the folding of an unstructured region of Ezh2 into an alpha helix, denoted as the stimulation response motif 
(SRM). This helix in turn stabilizes the SET-I helix which forms part of the substrate binding site of the Ezh2 SET domain. Overall, these results suggest that EED ligands may either act as positive allosteric modulators of Ezh2, if they fully mimic natural ligands and aid in folding the SRM helix, or potentially act as inhibitors if they: bind and do not stabilize the SRM helix, thereby blocking allosteric activation by endogenous EED ligands (neutral allosteric interaction); or bind and also disrupt substrate binding in the orthosteric, catalytic site (negative allosteric modulators). ${ }^{21}$

There is a growing interest in targeting chromatin-modifying enzymes with small molecules, and inhibitors for methyl-lysine (Kme) readers are similarly desirable as tools to elucidate the role of these readers in chromatin dysregulation and disease ${ }^{22-23}$. However, targeting the surface-groove binding mode of most Kme readers remains challenging, an issue exemplified by the dearth of chemical tools for studying Kme reader function. Currently, only two chemical probes of Kme readers have been published, while seven additional targets have literature on ligand development but lack adequate characterization, affinity, or cellular efficacy to be considered probes ${ }^{24-31}$. Of the two successful chemical probes, the discovery of a peptide-derived chemical probe, UNC3866, for the Polycomb repressive complex 1 (PRC1) chromodomain Kme3 readers has demonstrated the potential for selectively targeting these readers via cell permeable peptide mimetics ${ }^{32}$. Utilizing peptides as a foundation for inhibitor discovery offers several advantages including a rational starting point based on the native ligand. Additionally, our recent development of a combinatorial peptide platform to target Kme reader proteins enables rapid peptide optimization ${ }^{24}$. Such a combinatorial strategy for inhibitor discovery bypasses many of the drawbacks of a more traditional medicinal chemistry approach, namely cost, synthetic effort, and possible missed synergistic effects. Furthermore, compound libraries can be designed to improve ligand properties and competitor exchange kinetics can be applied to isolate ligands of equal or better potency. Thus, peptide ligand optimization provides an efficient and cost effective strategy for developing new chemical tools to study EED biology.

We present an in vitro chemical toolkit to study the role of EED's Kme reader function in the context of PRC2 activity. The pairing of combinatorial chemistry and structure-based design provides a platform for rapid optimization of ligand potency and chemical properties. This strategy enabled us to optimize the 12-mer Jarid2-K116me3 peptide to the 4-mer UNC5114, a $1 \mu \mathrm{M}$ EED binder. A biotinylated derivative effectively chemiprecipitated the core PRC2 components, EED, Suz12, and Ezh2, from cell lysates. Finally, we demonstrate that the targeted disruption of EED's reader function allosterically inhibits PRC2 catalytic activity. (While this manuscript was in revision a study reporting EED directed PRC2 inhibitors developed from an HTS hit appeared. ${ }^{33}$ )

\section{METHODS}

EED expression and purification (Library screening, ITC, FP assays)

The chromodomain of CBX7 (residues 8-65 of NP_055107) was expressed and purified as previously described ${ }^{32}$. Full length EED (reference sequence AAD08714) was expressed with an N-terminal His-tag in a pET28 vector. The pET28-EED expression construct was transformed into Rosetta2 BL21(DE3)pLysS competent cells (Novagen, EMD Chemicals, 
San Diego, CA). Protein expression was induced by growing cells at $37^{\circ} \mathrm{C}$ with shaking until the $\mathrm{OD}_{600}$ reached $\sim 0.6-0.8$ at which time the temperature was lowered to $15^{\circ} \mathrm{C}$ and expression was induced by adding $0.1 \mathrm{mM}$ IPTG and continuing shaking overnight. Cells were harvested by centrifugation and pellets were stored at $-80^{\circ} \mathrm{C}$.

His-tagged EED protein was purified by resuspending thawed cell pellets in $30 \mathrm{ml}$ of lysis buffer (50mM sodium phosphate $\mathrm{pH} 7.2,150 \mathrm{mM} \mathrm{NaCl}, 30 \mathrm{mM}$ imidazole, 1X EDTA free protease inhibitor cocktail (Roche Diagnostics, Indianapolis, IN)) per liter of culture. Cells were lysed on ice by sonication with a Branson Digital 450 Sonifier (Branson Ultrasonics, Danbury, CT) at $40 \%$ amplitude for 12 cycles with each cycle consisting of a 20 second pulse followed by a 40 second rest. The cell lysate was clarified by centrifugation and loaded onto a HisTrap FF column (GE Healthcare, Piscataway, NJ) that had been preequilibrated with 10 column volumes of binding buffer (50mM sodium phosphate $\mathrm{pH} 7.2$, $500 \mathrm{mM} \mathrm{NaCl}, 30 \mathrm{mM}$ imidazole) using an AKTA FPLC (GE Healthcare, Piscataway, NJ). The column was washed with 15 column volumes of binding buffer and protein was eluted in a linear gradient to $100 \%$ elution buffer $(50 \mathrm{mM}$ sodium phosphate $\mathrm{pH} 7.2,500 \mathrm{mM} \mathrm{NaCl}$, $500 \mathrm{mM}$ imidazole) over 20 column volumes. Peak EED containing fractions were pooled and concentrated to less than $8 \mathrm{ml}$ in Amicon Ultra-15 concentrators 10kDa molecular weight cut-off (Merck Millipore, Carrigtwohill Co. Cork IRL). Concentrated protein was loaded onto a HiLoad 26/60 Superdex 200 prep grade column (GE Healthcare, Piscataway, $\mathrm{NJ})$ that had been preequilibrated with 1.2 column volumes of sizing buffer $(25 \mathrm{mM}$ Tris $\mathrm{pH}$ 7.5, 500mM NaCl, 2mM DTT, 5\% glycerol) using an ATKA FPLC (GE Healthcare, Piscataway, NJ). Protein was eluted isocratically in sizing buffer over 1.3 column volumes at a flow rate of $2 \mathrm{ml} / \mathrm{min}$ collecting $3 \mathrm{ml}$ fractions. Peak fractions were analyzed for purity by SDS-PAGE and those containing pure protein were pooled and concentrated using Amicon Ultra-15 concentrators 10kDa molecular weight cut-off (Merck Millipore, Carrigtwohill Co. Cork IRL). Concentrated EED protein was dialyzed into a buffer containing $25 \mathrm{mM}$ Tris, $\mathrm{pH}$ $7.5,250 \mathrm{mM} \mathrm{NaCl}, 2 \mathrm{mM}$ DTT, $5 \%$ glycerol for storage.

\section{Library Screening}

For the first generation library, one-tenth of the synthesized library was removed to a $2 \mathrm{~mL}$ Eppendorf tube and equilibrated in $25 \mathrm{mM}$ Tris, $\mathrm{pH} 7.8,150 \mathrm{mM} \mathrm{NaCl}$, and $0.1 \%$ Tween-20 (TBST) overnight. All incubation steps were conducted at room temperature. Individual magnetic screens follow a similar protocol to that originally described by Astle et $\mathrm{al}^{2}$. For 1 hour, the beads were blocked in 5\% BSA in TBST $(1.8 \mathrm{~mL})$. The resin was washed three times in TBST (1.8 mL) followed by addition of $1 \mu \mathrm{M}$ His-tagged CBX7 (His6X-CBX7) in $2.5 \%$ BSA in TBST $(1.8 \mathrm{~mL})$ for 1 hour. Protein G Dynabeads (10 $\mu \mathrm{L}$; Life Technologies) were loaded with mouse anti-His antibody ( $2 \mu \mathrm{L}$ of a $1 \mu \mathrm{g} / \mu \mathrm{L}$ solution; Pierce MA1-21315) concurrently (1 hour). Excess antibody was removed and the Dynabeads were washed 3 times with TBST $(200 \mu \mathrm{L})$, and the library was also washed 3 times with TBST $(1.8 \mathrm{~mL})$. A solution of the anti-His antibody loaded Dynabeads in $2.5 \%$ BSA in TBST $(1.5 \mathrm{~mL})$ was added to the library, and the library beads and magnetic beads were left to rotate for hour. A magnet was used to separate $\mathrm{CBX} 7$ hits and nonspecific binders from the remaining library. To prepare for the subsequent EED screen, the remaining library was stripped with $1 \%$ SDS $(1.8 \mathrm{~mL})$ at $95^{\circ} \mathrm{C}$ for 3 minutes. The library was then rinsed with $0.1 \%$ Tween-20, $1 \mathrm{M}$ 
sodium chloride, and three times with TBST. The library was rotated in TBST overnight at $4^{\circ} \mathrm{C}$. The next day $1 \mu \mathrm{M}$ His6X-EED was screened as described above except magnetized hits from this screen were isolated and saved in a $0.6 \mathrm{~mL}$ Eppendorf tube. Hit PEGA beads were left to settle at the bottom of the tube while excess magnetic beads were removed by pulling off the solution by pipette. A solution of $10 \mu \mathrm{M}$ Jarid $2{ }_{114-118} \mathrm{~K} 116 \mathrm{me} 3$ in $2.5 \%$ BSA in TBST $(500 \mu \mathrm{M})$ was added to the hit beads. The hits were left to rotate in this solution for 2 hours, and the beads were subjected to a magnet and unmagnetized beads were removed to a separate Eppendorf tube. The hit beads that remained magnetized throughout the soluble competitor treatment were stripped with $1 \% \mathrm{SDS}$ at $95^{\circ} \mathrm{C}$ for 3 minutes then rinsed repeatedly with TBST followed by $0.1 \%$ Tween- 20 and finally rinsed and equilibrated overnight in ethanol.

The second generation library also employed a negative selection (His6X-CBX7) and target screening (His6X-EED) as described above, except $20 \mu \mathrm{L}$ Protein G Dynabeads was used with $4 \mu \mathrm{L}$ of anti-His antibody. Compound 2 was used as the soluble competitor.

\section{FP Assays}

Binding assays were carried out in buffer containing $20 \mathrm{mM}$ Tris (pH 7.5), $150 \mathrm{mM} \mathrm{NaCl}$, and $1 \mathrm{mM}$ CHAPS in black 384-well microplates (Greiner) with total reaction volumes of 25 $\mu \mathrm{L}$. To each well, $15 \mu \mathrm{L}$ of buffer was added followed by the addition of $5 \mu \mathrm{L}$ of a 2.000 , $1.000,0.500,0.250$, and $0.125 \mu \mathrm{M}$ compound 3-FAM. Serial dilutions of His6x-EED were prepared and $5 \mu \mathrm{L}$ was added to give final protein concentrations ranging from $0-50 \mu \mathrm{M}$. After 30 minutes at room temperature, FP measurements were taken on an AcQuest (LJL BioSystems) plate reader, with an excitation wavelength of $485 \mathrm{~nm}$ and the emission collected at $530 \mathrm{~nm}$. This 2D titration was run in duplicate and led to the selection of $50 \mathrm{nM}$ of compound 3-FAM and 1.5 $\mu \mathrm{M}$ of His6xEED as concentrations for follow-up displacement assays since. This combination was selected due to approximately $80 \%$ saturation of EED binding sites and a significant signal-to-noise window.

Displacement assays were conducted similarly, but with the following changes. First, $10 \mu \mathrm{L}$ of buffer was added before addition of $5 \mu \mathrm{L}$ of 0.250 compound 3-FAM and $5 \mu \mathrm{L}$ of $7.5 \mu \mathrm{M}$ His6x-EED. After 30 minutes, $5 \mu \mathrm{L}$ from serial dilutions $(0-100 \mu \mathrm{M})$ of each compound were added to the wells. The plate was left to incubate at room temperature for an additional 30 minutes and then read. Each reaction was run in triplicate or quadruplicate.

\section{ITC Experiments}

ITC measurements were recorded at $25^{\circ} \mathrm{C}$ using an AutoITC200 microcalorimeter (MicroCal Inc., MA). Protein stocks were prepared in ITC buffer $(25 \mathrm{mM}$ Tris-HCl, $\mathrm{pH} 8$, $250 \mathrm{mM} \mathrm{NaCl}$, and $2 \mathrm{mM} \beta$-mercaptoethanol) and then diluted into ITC buffer to achieve a final concentration of $50 \mu \mathrm{M}(325 \mu \mathrm{L})$. All compounds were dissolved in water to a stock concentration of $10 \mathrm{mM}$ and then diluted to a final concentration of $500 \mu \mathrm{M}$. A typical experiment included a single $0.2 \mu \mathrm{l}$ compound injection into a $200 \mu \mathrm{l}$ cell filled with protein, followed by 26 subsequent $1.5 \mu \mathrm{l}$ injections of compound. Injections were performed with a spacing of $180 \mathrm{~s}$ and a reference power of $8 \mu \mathrm{cal} / \mathrm{s}$. The titration data was analyzed using Origin Software (MicroCal Inc., USA) by nonlinear least-squares, fitting the heats of 
binding as a function of the compound:protein ratio to a one site binding model. The first data point was deleted from all analyses.

\section{PRC2 Complex Expression and Purification}

DNA fragments encoding the genes of the full lengths of two components of PRC2 complex, EED(1-441) and EZH2(1-751) were cloned into pFastBac-Dual (Invitrogen) and the full length of SUZ12(1-739) were cloned into pFastBac HT A (Invitrogen). The resulting plasmids were transformed into DH10Bac ${ }^{\mathrm{TM}}$ Competent E. coli (Invitrogen) and the recombinant viral DNA bacmids were purified and followed by a recombinant baculovirus generation in Sf9 insect cells. Sf9 cells grown in $\mathrm{HyQ}{ }^{\circledR S F X}$ insect serum-free medium (ThermoScientific) were co- infected with $10 \mathrm{ml}$ of each $\mathrm{P} 3$ viral stocks per $0.8 \mathrm{~L}$ of suspension cell culture and incubated at $27^{\circ} \mathrm{C}$ using a platform shaker set at $100 \mathrm{RPM}$. The cells were collected after 72 hours of post infection time, when viability dropped to 70-80\%. Harvested cells were re-suspended in PBS, 1 X protease inhibitor cocktail $(2.5 \mu \mathrm{g} / \mathrm{ml}$ Aprotinin, $2.5 \mu \mathrm{g} / \mathrm{ml}$ Leupeptin, $2.5 \mu \mathrm{g} / \mathrm{ml}$ Pepstatin A and $2.5 \mu \mathrm{g} / \mathrm{ml}$ E-64) or a complete EDTA-free protease inhibitor cocktail tablet (Roche). The cells were lysed chemically by rotating 30 min with NP-40 (final concentration of $0.6 \%$ ) and $50 \mathrm{U} / \mathrm{mL}$ Benzonase nuclease (Sigma) and $2 \mathrm{mM} 2$-mercaptoethanol followed by sonication at frequency of 8 (10 sec on/10 sec off) for $4 \mathrm{~min}$ (Sonicator 3000, Misoni). The crude extract was clarified by highspeed centrifugation $\left(60 \mathrm{~min}\right.$ at $36,000 \times \mathrm{g}$ at $4^{\circ} \mathrm{C}$ ) in a Beckman Coulter centrifuge. The recombinant protein complex was purified by incubating the cleared lysate with equilibrated Anti-FLAG M2 Affinity agarose gel (Sigma, Cat \# A2220) for 1.5 hours with rotating, followed by washing with 10 column volumes of TBS $(50 \mathrm{mM}$ Tris- $\mathrm{HCl}$, with $150 \mathrm{mM}$ $\mathrm{NaCl}, \mathrm{pH}$ 7.4). The recombinant protein complex was eluted by competitive elution with $100 \mu \mathrm{g} / \mathrm{ml}$ FLAG peptide (Sigma, Catalog \# F4799) in TBS and 5\% glycerol. Purity was judged by SDS-PAGE and the protein was subsequently concentrated and flash frozen. Aromatic cage mutations of EED in this PRC 2 construct were also created by site-directed mutagenesis as described for the EED single constructs. PRC2 complexes containing these EED mutations were expressed and purified as the wildtype.

\section{PRC2 Methyltransferase Activity Assay}

Methyltransferase activity assays for EZH2 trimeric complex (EZH2:EED:SUZ12) were performed by monitoring the incorporation of tritium-labeled methyl group to lysine 27 of H3 (21-44) peptide using Scintillation Proximity Assay (SPA). The enzymatic reactions were performed at $23{ }^{\circ} \mathrm{C}$ with 1 hour incubation of $10 \mu \mathrm{l}$ reaction mixture in $20 \mathrm{mM}$ Tris$\mathrm{HCl}, \mathrm{pH} 8,5 \mathrm{mM}$ DTT, and $0.01 \%$ Triton X-100 containing $1 \mu \mathrm{M}$ of ${ }^{3} \mathrm{H}-\mathrm{SAM}$ (Cat.\# NET155V250UC; Perkin Elmer; www.perkinelmer.com), $1 \mu \mathrm{M}$ of biotinylated H3 (21-44), $20 \mathrm{nM}$ EZH2 complex, and compound titration from $50 \mu \mathrm{M}$ to $50 \mu \mathrm{M}$. To stop the reactions, $10 \mu \mathrm{L}$ of $7.5 \mathrm{M}$ Guanidine hydrochloride was added, followed by $200 \mathrm{Gl}$ of buffer $(20 \mathrm{mM}$ Tris, pH 8.0), mixed and transferred to a 96-well Streptavidin coated Flash-plate (PerkinElmer,http://www.perkinelmer.ca). After mixing, Flash-plates were incubated for 2 hour and the CPM counts were measured using Topcount plate reader (Perkin Elmer, www.perkinelmer.com). The CPM counts in the absence of compound for each dataset were defined as $100 \%$ activity. In the absence of the enzyme, the CPM counts in each data set were defined as background (0\%). All enzymatic reactions were performed in triplicate and 
$\mathrm{IC}_{50}$ values were determined by fitting the data to Four Parameter Logistic equation using GraphPad Prism 7 software.

For competition experiments with H3K27me3 peptide, 0, 1 or $10 \mu \mathrm{M}$ H3K27me3 (19-33) peptide were included in the reaction mixture. For data sets involving comparison of the wildtype complex activity against those of the mutants, the CPM counts of the wildtype complex in the absence of compound were defined as $100 \%$ activity. In the absence of the enzyme, the CPM counts in each data set were defined as background ( $0 \%)$. The enzymatic reactions were performed in triplicate and $\mathrm{IC}_{50}$ values were determined by fitting the data to Four-Parameter Logistic equation using SigmaPlot version 11.0.

Additional methods, including compound synthesis and characterization, crystallography, and pull-down experiments, are described in the Supporting Information.

\section{RESULTS AND DISCUSSION}

The recent characterization of EED's binding to methylated Jarid2 at low micromolar potency (Jarid2 $\left.{ }_{110-120}-\mathrm{K} 116 \mathrm{me} 3, K_{d} \sim 3 \mu \mathrm{M}\right)^{18}$ provided a rational starting point for peptide optimization to target the reader interface of EED. We initially set out to design and test the affinity of a truncated Jarid2-K116me3 peptide. By analyzing the co-crystal structure of Jarid2-K116me3 and EED (PDB 4X3E) we noted that the majority of specific proteinprotein contacts were largely confined to five residues within Jarid2 (Jarid2 ${ }_{114-118} \mathrm{~K} 116 \mathrm{me} 3$, Figure 1a). Distinctively, the glutamine 114 side chain rests in a small hydrophobic pocket while the backbone carbonyl appears to make a hydrogen bond with tryptophan 364 of the EED aromatic cage. K116me3 binds in the aromatic cage while its carbonyl and that of the adjacent arginine 115 form additional hydrogen bonds with EED. Unlike the H3K27 sequence, Jarid ${ }_{114-118} \mathrm{~K} 116 \mathrm{me} 3$ contains a phenylalanine at the +1 position adjacent to the methylated lysine. Phenylalanine 117 was shown to be essential for Jarid2 binding and the crystal structure demonstrates that the aromatic ring is positioned to either stack with phenylalanine 97 of the aromatic cage or to further enclose K116me 3 within the cage. Lastly, alanine 118 of Jarid2 binds in a shallow hydrophobic patch on EED's surface. We synthesized Jarid ${ }_{114-118} \mathrm{~K} 116 \mathrm{me} 3$ and tested its affinity for EED by isothermal titration calorimetry (ITC) $\left(K_{d}=8.82 \pm 2.06 \mu \mathrm{M}\right.$; Supplementary Information Figure S1). The truncated peptide demonstrated less than a 3-fold loss in affinity compared to the published value for Jarid2 $110-120^{-K} 116 \mathrm{me} 3$, confirming that the bulk of EED's affinity for Jarid2$\mathrm{K} 116 \mathrm{me} 3$ is due to contacts with these five residues.

To confirm EED's compatibility with our on-bead, magnetic enrichment screening approach (Figure 1b), Jarid2 ${ }_{114-121^{-K} 116 m e 3}$ was synthesized on PEGA resin (Jarid2 ${ }_{114-121^{-}}$ K116me3-PEGA) as a control ligand ${ }^{24,34}$. Histone peptides, with their high charge density and numerous arginines, lysines and glutamines, interact non-specifically with the components of the on-bead assay. The longer Jarid2 peptide seemed likely to face similar issues, which led us to select a truncated Jarid2 peptide sequence for on-bead screen development. Though the longer peptide is unnecessary for maintaining affinity to EED, the additional residues serve as a spacer between the methionine required for cyanogen bromide $(\mathrm{CNBr})$ cleavage and the protein-binding region of the peptide. Following our previous Kme 
reader screening protocol ${ }^{24}$, His-tagged EED (His6X-EED) was incubated with bovine serum albumin-blocked Jarid2 114-121-K116me3-PEGA. Simultaneously, mouse anti-His6X antibody was bound to magnetic Protein G Dynabeads. Following extensive washing, the antibody-coated Dynabeads were added to the preincubated Jarid2 ${ }_{114-121}$-K116me3-PEGA resin. Jarid2 $114-121^{-K} 116 m e 3-P E G A$ became selectively magnetized only in the presence of His6X-EED, as expected. In contrast, UNC3866-PEGA failed to become magnetized in either the presence or absence of His6X-EED which recapitulated EED's lack of affinity for UNC3866 in solution-based assays ${ }^{32}$ and helped to confirm that successful magnetization occurs only in the presence of genuine EED ligands.

Having established the peptide region of Jarid2 that we planned to optimize and validated EED in our magnetic enrichment assay, we began designing a first generation combinatorial library of potential EED ligands (Figure 1c). Our initial library design focused on improving the undesirable properties of Jarid $2_{114-118} \mathrm{~K} 116 \mathrm{me} 3$, namely the presence of a primary amine at the $\mathrm{N}$-terminus, a quaternary amine, a guanidinyl group, and an overall +3 charge state. Our library tested a variety of carboxylic acid caps at the $\mathrm{N}$-terminus as replacements for glutamine 114, while also including an acetyl-capped glutamine in case this residue was required for EED activity. Previous studies indicated that an arginine at the -1 position of Kme3 was essential for stimulation of PRC2 catalytic activity though unnecessary for binding to $E E D^{16-17}$. Potential arginine replacements in our library included serine and alanine, for example, as well as riskier substitutions including peptoid residues in an attempt to reduce the number of backbone hydrogen bond donors. A variety of natural and unnatural aromatic residues were tested in place of Phe at the R4 position, while only modest changes were included at the Kme3 position.

Using split-and-pool synthesis ${ }^{35}$, the 1,029 compound library was synthesized at approximately 20 -fold redundancy (Figure $1 \mathrm{c}$ ). To diminish the resynthesis of false positives we included multiple copies of each potential ligand in the library so that hits could be prioritized by redundancy for follow-up studies ${ }^{36}$. Kme derivatives were synthesized via reductive amination with lysine to form the tertiary amines followed by substitution to yield the desired quaternary amines. Incorporation of methionine as the first residue of the linker enabled cyanogen bromide $(\mathrm{CNBr})$ cleavage from the resin for hit deconvolution by MALDI MS/MS. Amino acids were added via standard Fmoc solid phase synthesis while peptoids were synthesized by bromoacetic acid coupling and then substitution with a primary amine. Deprotection of the pooled library to remove Boc/tBu groups was conducted under acidic conditions, and then the final library was equilibrated in aqueous buffer prior to screening.

A preliminary negative selection of the library was conducted with the chromodomain of CBX7, a Kme reader also known to bind H3K27me3. Magnetized beads were presumed to either bind nonspecifically to the components of the assay (Protein G Dynabeads and antiHis6x antibody) or specifically to CBX7. Magnetized beads were removed from the library while the unmagnetized beads were carried forward, and His6X-EED was then screened against the remaining library. Magnetically isolated EED hit beads were separated and treated with a soluble competitor ligand, Jarid ${ }_{114-118} \mathrm{~K} 116 \mathrm{me} 3(10 \mu \mathrm{M})$, to elute off low affinity hits and retain only those ligands with improved potency over the truncated Jarid 2 
peptide. After 120 minutes, those hits that remained magnetized were isolated, stripped, and cleaved from the bead with $\mathrm{CNBr}$ before being sequenced by tandem mass spectrometry.

Two hits were isolated with a greater than 2-fold redundancy (Figure 1d; Supplementary Information Figure S2), both of which included cyclohexane carboxylic acid as a glutamine replacement at the $\mathrm{N}$-terminus. At positions R4 and R3, respectively, phenylalanine and Kme3 residues were conserved, but the hits varied at the $\mathrm{R} 2$ position containing either a lysine or serine. After resynthesis of compound $\mathbf{1}$, hit confirmation by ITC demonstrated a slight improvement in potency relative to Jarid2 ${ }_{114-118} \mathrm{~K} 116 \mathrm{me} 3$ (compound 1: $K_{\mathrm{d}}=4.74$ $\pm 0.69 \mu \mathrm{M}$ vs Jarid $2_{114-118} \mathrm{~K} 116 \mathrm{me} 3: K_{\mathrm{d}}=8.82 \pm 2.06 \mu \mathrm{M}$; Supplementary Information Figure $\mathrm{S} 1$ ). In addition to replacing the $\mathrm{N}$-terminal amine and the glutamine side chain primary amide, both ligands also revealed suitable replacements for the guanidinyl group of arginine. Overall, this first generation EED-targeted library resulted in improved ligand potency and physicochemical properties while important insights were gained into the amenability of replacing the two $\mathrm{N}$-terminal residues.

We next designed a larger second generation library consisting of 4,410 compounds taking into account insights from our initial screening results (Figure 2). The goal of this library was primarily to improve ligand affinity so both conservative and riskier modifications were tested at positions R1, R2, R4, and R5 while only Kme3 was incorporated at position R3. For instance, several phenylalanine derivatives were included at position R4 to potentially improve the interaction of the ring with the aromatic cage or the Kme3 side chain. We included a deeper exploration of cyclic analogs at the $\mathrm{N}$-terminal capping position based on conservation of the cyclohexyl cap in both hits of the first generation library. Additionally, while the C-terminal alanine was not altered in the previous library, a variety of residues with small hydrophobic side chains were included in the second generation library to probe a small hydrophobic patch on EED's surface. Additionally, the second generation library included a modified linker. Firstly, an alkyne was included because previous studies ${ }^{37-38}$ had applied this strategy to derivatize ligands after bead cleavage, though our approach in this study did not employ this group. Secondly, alanine and beta-alanine were included in the linker to provide space between the compound and the methionine and the alkyne. Since this library sought only to probe the affinity of the 5-mer peptide, the native sequence was not used as the linker to avoid any effects this sequence might have on affinity.

Screening followed an identical protocol as described above with the substitution of compound $\mathbf{2}$ as the soluble competitor. Nine ligands with a redundancy greater than 2-fold were isolated, and a number of structural similarities were observed (a subset are shown in Supplementary Information Figure S3). The capping residue (R1) favored aliphatic heterocycles while significant tolerance was found at the R2 position. Although two hits with 3-fluorophenylalanine at R4 were identified, retention of phenylalanine was clearly preferred. Lastly, the R5 position favored either leucine or valine suggesting that increased hydrophobic contacts at the $\mathrm{C}$-terminus improve the interaction between the peptide and EED. Based on these hit structures, we synthesized a peptide combining the residues that appeared most frequently (compound $3 ; K_{d}=1.09 \pm 0.27 \mu \mathrm{M}$; Supplementary Information Figure S1) which resulted in an approximately 4-fold enhancement in affinity compared to compound 1 (Figure 3a). By applying combinatorial optimization to Jarid2 ${ }_{114-118} \mathrm{~K} 116 \mathrm{me} 3$, 
only two iterations of library design and screening reduced the overall ligand charge from +3 to +2 and produced a 10 -fold improvement in potency.

We next solved the co-crystal structure of compound 3 bound to EED (Figure 3b, (PDB 5TTW)). Unsurprisingly, the Kme3 and phenylalanine residues adopt an identical binding mode to Jarid2K116me3 (PDB 4X3E). Interestingly, the C-terminus binds in a unique orientation that positions the hydrophobic leucine side group toward EED's surface (Figure $3 \mathrm{c}, \mathrm{d})$. The isoleucine 363 side chain and the carbon chain of glutamine 382 form van der Waal contacts with the leucine side chain of $\mathbf{3}$ while the backbone primary amide does not interact with EED. Although the amide bond between phenylalanine and leucine in compound $\mathbf{3}$ does not appear to make specific hydrogen bond contacts, the carbonyls of lysine and serine form hydrogen bonds with residues at the base of EED's aromatic cage. Additionally, while the serine backbone seems critical for bridging the methylated lysine within the aromatic cage and the proline that interacts with a small hydrophobic pocket formed by asparagine 307 , tyrosine 308 , and cysteine 324 , the side chain of serine has no apparent interactions, suggesting this group is non-essential for binding. This is consistent with the variability observed at this position in both libraries. Overall, the co-crystal structure strongly implicated the potential for replacing the leucine of compound $\mathbf{3}$ with a non-peptidic, hydrophobic group and replacement of the proline-serine $\mathrm{N}$-terminus.

In the next phase of optimization, we C-terminally labeled compound $\mathbf{3}$ with fluorescein to enable an EED fluorescence polarization (FP) assay (Supplementary Information Figure S4a). Following optimization of protein and fluorescent ligand concentrations (Supplementary Information Figure S4b), we validated this assay by displacing the bait peptide with compound 3 , and an $\mathrm{IC}_{50}(1.65 \pm 0.66 \mu \mathrm{M})$ approximately the same as the $K_{d}$ $(1.09 \pm 0.27 \mu \mathrm{M})$ was observed (Table 1; curves shown in Supplementary Information Figure S5). Similarly, Jarid2 ${ }_{114-118} \mathrm{~K} 116 \mathrm{me} 3$ demonstrated an $\mathrm{IC}_{50}(14.78 \pm 2.24 \mu \mathrm{M})$ on par with its measured $K_{d}(8.82 \pm 2.06 \mu \mathrm{M})$ so we moved forward by testing new compounds via FP followed by ITC characterization for the most promising ligands.

Subsequent compound optimization focused on modifying the two termini to reduce the length of the peptide and replacing the quaternary amine. Initially, the C-terminal leucine was replaced by a piperidinyl ring (compound 4). This substitution had minimal effects on potency indicating that the piperidine ring could mimic important hydrophobic contacts made by the leucine side chain while both the C-terminal amide and the backbone amide proton of the leucine residue were not required for EED binding. Next, since quaternary amines are suggested to prevent passive diffusion through the lipid bilayer, the trimethyl substitution on the lysine was replaced by various tertiary amines including diethyl (5), methyl-cyclohexyl (6), and methyl-isopropyl (7). When compared to Kme3, the corresponding methyl-cyclohexyl ligand lost nearly all binding to $\mathrm{EED}\left(\mathrm{IC}_{50}>30 \mu \mathrm{M}\right)$ whereas the diethyl-lysine-containing ligand resulted in a 7-fold reduction in potency. Methyl-isopropyl was found to be the best substitute for Kme3 with only a 3-fold loss in affinity. Following selection of methyl-isopropyl lysine (Kme,iPr) for further optimization, three bicyclic capping residues were tested to replace the proline-serine $\mathrm{N}$-terminus. While two of the capping residues containing aromatic rings to potentially stack with tryptophan 364 or tyrosine 308 did not potently interact with EED (compounds 8 and 9), an (2S,3aS, 
7aS)-octahydro-1H-indole cap (compound 10, UNC5114) not only maintained EED affinity but even compensated for the slight loss in potency due to the Kme,iPr substitution. Incorporating the C-terminal piperidinyl ring into UNC5114 (compound 11, UNC5115) resulted in a 2-fold loss in potency relative to UNC5114. Follow-up ITC experiments confirmed UNC5114 $\left(K_{d}=0.68 \pm 0.05\right)$ and UNC5115 $\left(K_{d}=1.14 \pm 0.14\right)$ potencies. Additionally, we speculated that methylation of the phenylalanine amide in UNC5115 would disrupt the ability of the phenyl ring to fold over the aromatic cage and the lysine side chain, thus abolishing EED binding. UNC5197 (Figure 4a) ITC data confirmed that this methylation disrupts binding and hence this compound represents an ideal negative control for subsequent studies. Overall, UNC5114 contains only three hydrogen bond donors and a +2 charge state which is a dramatic improvement over the 5 -mer Jarid ${ }_{114-118} \mathrm{~K} 116 \mathrm{me} 3$ ligand that includes nine hydrogen bond donors and $a+3$ charge state.

Having discovered of a set of peptide-competitive chemical tools with low micromolar to high nanomolar in vitro affinities for EED, we next sought to investigate how targeted disruption of the PRC2 reader function would alter catalytic activity of the complex. Although previous studies have demonstrated allosteric activation of PRC2 catalytic activity by several methylated peptides, we hypothesized that our ligands would not be stimulatory because they lack the requisite arginine at the -1 position to Kme 3 that is required for stabilization of the SRM helix. We moved forward by characterizing the effects of compound 3, UNC5114, and UNC5115 in a PRC2 methyltransferase scintillation proximity assay $^{12}$ (Figure $4 b$ ). In brief, this assay monitors the transfer of a tritiated methyl group from the cofactor S-adenosyl methionine to a histone $\mathrm{H}_{21-44} \mathrm{~K} 27$ unmodified peptide.

Interestingly, all three ligands inhibit catalytic activity, albeit to only about $80 \%$ at saturating concentrations of ligand. We believe this residual $20 \%$ activity may correspond to a basal activity of the unstimulated Ezh2 enzyme within the PRC2 core complex, as direct inhibition of Ezh2 catalytic domain with SAM-competitive inhibitors completely eliminates enzyme activity $10,11,12,13$.

To biochemically probe the allosteric inhibition of PRC2 via binding to the EED reader pocket, UNC5114 and UNC5115 were incubated with the PRC2 core complex in the presence or absence of the stimulatory $\mathrm{H} 3 \mathrm{~K} 27 \mathrm{me} 3$ peptide. Increasing concentrations of the $\mathrm{H} 3 \mathrm{~K} 27 \mathrm{me} 3$ peptide increased the activity of the enzyme but also increased the apparent $\mathrm{IC}_{50}$ values of both compounds (Figure 5). These results are consistent with a mechanism of action in which the compounds inhibit PRC2 by competing with the stimulatory peptide, thereby preventing allosteric stimulation of the enzyme. EED aromatic cage mutants (F97A, W364A, and Y365A) were also generated to further test this mechanism of PRC2 inhibition. Differential static light scattering (DSLS) confirmed that all three mutants demonstrated a similar thermal aggregation stability profile to wild-type EED, suggesting that these mutants are properly folded (Supporting Information Figure S6). When reconstituted into a core PRC2 complex, the EED mutants exhibit significantly lower levels of basal catalytic activity, and UNC5114 and UNC5115 clearly fail to inhibit this activity whereas the EZH2 chemical probe UNC1999 completely abrogates the activity (Supporting Information Figure S7), similar to its inhibition of wildtype PRC2. Taken together, these results demonstrate that 
UNC5114 and UNC5115 act as allosteric inhibitors of PRC2 methyltransferase activity through competitive inhibition of the EED Kme reader function.

In order to confirm that UNC5114 and UNC5115 are able to target native PRC2 from cells, we biotinylated UNC5114 to attempt chemiprecipitation of PRC2 components from cellular lysates (Figure 6a). Streptavidin coated magnetic Dynabeads were incubated with biotinylated UNC5114 followed by the addition of PC-3 cell lysates in the presence and absence of soluble UNC5114 to confirm the specificity of the pulldown. Western blot analysis indicated successful pulldown of all three core components of PRC2: EED, Ezh2, and Suz12 (Figure 6b). These results confirm that biotin-UNC5114 engages the Kme reader pocket of EED without disrupting assembly of the PRC2 complex and that our ligands bind endogenous EED.

\section{CONCLUSIONS}

A paired combinatorial and structure-based optimization strategy led to the discovery of two small, peptidomimetic ligands of EED. These ligands exhibit improved potency ( 10 -fold) and physicochemical properties compared to Jarid $2_{114-118} \mathrm{~K} 116 \mathrm{me} 3$, and they demonstrate the feasibility of optimizing a peptidic antagonist of a Kme reader domain for targeted disruption of its reader function. Moreover, compound $\mathbf{3}$ could be easily functionalized to facilitate the development of an FP assay, and UNC5114-biotin enabled chemiprecipitation experiments that show maintenance of affinity for endogenous EED. Most interestingly, the disruption of PRC2 catalytic activity by UNC5114 and UNC5115 presents a unique opportunity to probe allosteric regulation of $\mathrm{H} 3 \mathrm{~K} 27 \mathrm{me} 3$ deposition particularly when considering that the allosteric mechanisms governing PRC2 are only beginning to be understood. It is possible that, in addition to competitively preventing allosteric activation, these peptidomimetic EED ligands disrupt catalytic activity by preventing the stabilization and orientation of the stimulation response motif (SRM) helix of EZH2 as described by Jiao and Liu ${ }^{15}$ (Figure 7). Consequently, the SRM helix cannot in turn stabilize the SET-I helix which contributes many of the residues that interact with the substrate peptide, as required for more efficient catalytic activity. Further dissection of this mechanism and determination of whether these ligands are neutral allosteric modulators or negative allosteric modulators will depend upon definition of the structural changes in PRC2 upon binding of these compounds. ${ }^{21}$ Ultimately, these ligands recapitulate the centrality of EED to the catalytic output of PRC2.

\section{Supplementary Material}

Refer to Web version on PubMed Central for supplementary material.

\section{Acknowledgments}

We thank N. Dicheva and the UNC Michael Hooker Proteomics Center for assistance with and use of their AbSciex 5800 MALDI-TOF/TOF. The authors acknowledge M. Ravichandran, S. Duan, and T. Hajian for EED mutant constructs and assistance with protein purification, and $\mathrm{W}$. Tempel for reviewing crystallography data. The research described here was supported by the National Institute of General Medical Sciences, U.S. National Institutes of Health (NIH, grant R01GM100919) and the University Cancer Research Fund, University of North Carolina at Chapel Hill. The SGC is a registered charity (number 1097737) that receives funds from AbbVie, Bayer Pharma AG, Boehringer Ingelheim, Canada Foundation for Innovation, Eshelman Institute for Innovation, Genome Canada, 
Innovative Medicines Initiative (EU/EFPIA) [ULTRA-DD grant no. 115766], Janssen, Merck \& Co., Novartis Pharma AG, Ontario Ministry of Economic Development and Innovation, Pfizer, São Paulo Research FoundationFAPESP, Takeda, and the Wellcome Trust.

\section{ABBREVIATIONS}

EED

embryonic ectoderm development

PRC2

Polycomb repressive complex 2

H3K27me3

histone $\mathrm{H} 3$ lysine 27 trimethylation

$\boldsymbol{K}_{\boldsymbol{d}}$

dissociation constant

Jarid2

Jumonji/ARID domain-containing protein 2

\section{Ezh1/2}

enhancer of zeste homolog $1 / 2$; supressor of zeste 12 protein homolog

\section{RbAp46/48}

retinoblastoma-binding protein $46 / 48$

\section{H1K26me3}

histone $\mathrm{H} 1$ lysine 26 trimethylation

Jarid2-K116me3

Jarid2 trimethylated at lysine 116

\section{SRM}

stimulation response motif

SET

Su(var) and 'Enhancer of zeste' proteins

SET-I

SET inhibitory

PRC1

Polycomb repressive complex 1

Kme

methyl-lysine

Jarid2 $110-120$-K116me3

Jarid2 peptide residues 110-120 trimethylated lysine 116me3 


\section{Jarid2 ${ }_{114-118}$ K116me3}

Jarid2 peptide residues 114-118 trimethylated lysine 116me3

ITC

isothermal titration calorimetry

\section{His6X-EED}

His-tagged EED

\section{$\mathrm{CNBr}$}

cyanogen bromide

\section{CBX7}

chromobox protein homolog 7

\section{FP}

fluorescence polarization

$\mathrm{IC}_{50}$

half maximal inhibitory concentration

iPr

isopropyl

\section{References}

1. Cao R, Wang L, Wang H, Xia L, Erdjument-Bromage H, Tempst P, Jones RS, Zhang Y. Role of Histone H3 Lysine 27 Methylation in Polycomb-Group Silencing. Science. 2002; 298(5595):1039_ 1043. [PubMed: 12351676]

2. Varambally S, Dhanasekaran SM, Zhou M, Barrette TR, Kumar-Sinha C, Sanda MG, Ghosh D, Pienta KJ, Sewalt RG, Otte AP. The polycomb group protein EZH2 is involved in progression of prostate cancer. Nature. 2002; 419(6907):624-629. [PubMed: 12374981]

3. Pasini D, Bracken AP, Jensen MR, Denchi EL, Helin K. Suz12 is essential for mouse development and for EZH2 histone methyltransferase activity. The EMBO journal. 2004; 23(20):4061-4071. [PubMed: 15385962]

4. Montgomery ND, Yee D, Chen A, Kalantry S, Chamberlain SJ, Otte AP, Magnuson T. The Murine Polycomb Group Protein Eed Is Required for Global Histone H3 Lysine-27 Methylation. Curr Biol. 2005; 15(10):942-947. [PubMed: 15916951]

5. Margueron R, Reinberg D. The Polycomb complex PRC2 and its mark in life. Nature. 2011; 469(7330):343-349. [PubMed: 21248841]

6. Aranda S, Mas G, Di Croce L. Regulation of gene transcription by Polycomb proteins. Sci Adv. 2015; 1(11):e1500737. [PubMed: 26665172]

7. Conway E, Healy E, Bracken AP. PRC2 mediated H3K27 methylations in cellular identity and cancer. Curr Opin Cell Biol. 2015; 37:42-48. [PubMed: 26497635]

8. Lund K, Adams PD, Copland M. EZH2 in normal and malignant hematopoiesis. Leukemia. 2014; 28(1):44-49. [PubMed: 24097338]

9. Lewis PW, Müller MM, Koletsky MS, Cordero F, Lin S, Banaszynski LA, Garcia BA, Muir TW, Becher OJ, Allis CD. Inhibition of PRC2 activity by a gain-of-function $\mathrm{H} 3$ mutation found in pediatric glioblastoma. Science. 2013; 340(6134):857-861. [PubMed: 23539183]

10. McCabe MT, Ott HM, Ganji G, Korenchuk S, Thompson C, Van Aller GS, Liu Y, Graves AP, Diaz E, LaFrance LV. EZH2 inhibition as a therapeutic strategy for lymphoma with EZH2-activating mutations. Nature. 2012; 492(7427):108-112. [PubMed: 23051747] 
11. Qi W, Chan H, Teng L, Li L, Chuai S, Zhang R, Zeng J, Li M, Fan H, Lin Y, Gu J, Ardayfio O, Zhang JH, Yan X, Fang J, Mi Y, Zhang M, Zhou T, Feng G, Chen Z, Li G, Yang T, Zhao K, Liu X, Yu Z, Lu CX, Atadja P, Li E. Selective inhibition of Ezh2 by a small molecule inhibitor blocks tumor cells proliferation. P Natl Acad Sci USA. 2012; 109(52):21360-5.

12. Konze KD, Ma A, Li F, Barsyte-Lovejoy D, Parton T, MacNevin CJ, Liu F, Gao C, Huang X-P, Kuznetsova E. An orally bioavailable chemical probe of the lysine methyltransferases EZH2 and EZH1. ACS Chem Biol. 2013; 8(6):1324-1334. [PubMed: 23614352]

13. Campbell JE, Kuntz KW, Knutson SK, Warholic NM, Keilhack H, Wigle TJ, Raimondi A, Klaus CR, Rioux N, Yokoi A. EPZ011989, a potent, orally-available EZH2 inhibitor with robust in vivo activity. ACS Med Chem Lett. 2015; 6(5):491-495. [PubMed: 26005520]

14. Kim KH, Roberts CW. Targeting EZH2 in cancer. Nature medicine. 2016; 22(2):128-134.

15. Jiao L, Liu X. Structural basis of histone H3K27 trimethylation by an active polycomb repressive complex 2. Science. 2015; 350(6258)

16. Margueron R, Justin N, Ohno K, Sharpe ML, Son J, Drury WJ III, Voigt P, Martin SR, Taylor WR, De Marco V, Pirrotta V, Reinberg D, Gamblin SJ. Role of the polycomb protein EED in the propagation of repressive histone marks. Nature. 2009; 461(7265):762-767. [PubMed: 19767730]

17. Xu C, Bian C, Yang W, Galka M, Ouyang H, Chen C, Qiu W, Liu H, Jones AE, MacKenzie F, Pan P, Li SS-C, Wang H, Min J. Binding of different histone marks differentially regulates the activity and specificity of polycomb repressive complex 2 (PRC2). P Natl Acad Sci USA. 2010; 107(45): 19266-19271.

18. Sanulli S, Justin N, Teissandier A, Ancelin K, Portoso M, Caron M, Michaud A, Lombard B, Da Rocha ST, Offer J. Jarid2 methylation via the PRC2 complex regulates H3K27me3 deposition during cell differentiation. Mol Cell. 2015; 57(5):769-783. [PubMed: 25620564]

19. Justin N. Structural basis of oncogenic histone H3K27M inhibition of human polycomb repressive complex 2. Nat Comm. 7:11316.

20. Brooun A, Gajiwala KS, Deng Y-L, Liu W, Bolaños B, Bingham P, He Y-A, Diehl W, Grable N, Kung P-P. Polycomb repressive complex 2 structure with inhibitor reveals a mechanism of activation and drug resistance. Nat Comm. 2016:7.

21. Christopoulos A, Changeux J-P, Catterall WA, Fabbro D, Burris TP, Cidlowski JA, Olsen RW, Peters JA, Neubig RR, Pin J-P, Sexton PM, Kenakin TP, Ehlert FJ, Spedding M, Langmead CJ. International Union of Basic and Clinical Pharmacology. XC. Multisite Pharmacology: Recommendations for the Nomenclature of Receptor Allosterism and Allosteric Ligands. Pharmacol Rev. 2014; 66(4):918. [PubMed: 25026896]

22. Frye SV, Heightman T, Jin J. Targeting methyl lysine. Annu Rep Med Chem. 2010; 45:329-343.

23. Arrowsmith CH, Bountra C, Fish PV, Lee K, Schapira M. Epigenetic protein families: a new frontier for drug discovery. Nat Rev Drug Discov. 2012; 11(5):384-400. [PubMed: 22498752]

24. Barnash KD, Lamb KN, Stuckey JI, Norris JL, Cholensky SH, Kireev DB, Frye SV, James LI. Chromodomain Ligand Optimization via Target-Class Directed Combinatorial Repurposing. ACS Chem Biol. 2016; 11(9):2475-2483. [PubMed: 27356154]

25. Herold JM, James LI, Korboukh VK, Gao C, Coil KE, Bua DJ, Norris JL, Kireev DB, Brown PJ, Jin J. Structure-activity relationships of methyl-lysine reader antagonists. MedChemComm. 2012; $3(1): 45-51$.

26. Miller TC, Rutherford TJ, Birchall K, Chugh J, Fiedler M, Bienz M. Competitive binding of a benzimidazole to the histone-binding pocket of the Pygo PHD finger. ACS Chem Biol. 2014; 9(12):2864-2874. [PubMed: 25323450]

27. Milosevich N, Gignac MC, McFarlane J, Simhadri C, Horvath S, Daze KD, Croft CS, Dheri A, Quon TT, Douglas SF. Selective Inhibition of CBX6: A Methyllysine Reader Protein in the Polycomb Family. ACS Med Chem Lett. 2015; 7(2):139-144. [PubMed: 26985288]

28. Perfetti MT, Baughman BM, Dickson BM, Mu Y, Cui G, Mader P, Dong A, Norris JL, Rothbart $\mathrm{SB}$, Strahl BD. Identification of a fragment-like small molecule ligand for the methyl-lysine binding protein, 53BP1. ACS Chem Biol. 2015; 10(4):1072-1081. [PubMed: 25590533]

29. Ren C, Morohashi K, Plotnikov AN, Jakoncic J, Smith SG, Li J, Zeng L, Rodriguez Y, Stojanoff V, Walsh M. Small-molecule modulators of methyl-lysine binding for the CBX7 chromodomain. Chem Biol. 2015; 22(2):161-168. [PubMed: 25660273] 
30. Wagner EK, Nath N, Flemming R, Feltenberger JB, Denu JM. Identification and characterization of small molecule inhibitors of a plant homeodomain finger. Biochemistry. 2012; 51(41):82938306. [PubMed: 22994852]

31. Wagner T, Greschik H, Burgahn T, Schmidtkunz K, Schott A-K, McMillan J, Baranauskienė L, Xiong Y, Fedorov O, Jin J. Identification of a small-molecule ligand of the epigenetic reader protein Spindlin1 via a versatile screening platform. Nucleic Acids Res. 2016; 44(9):e88-e88. [PubMed: 26893353]

32. Stuckey JI, Dickson BM, Cheng N, Liu Y, Norris JL, Cholensky SH, Tempel W, Qin S, Huber KG, Sagum C. A cellular chemical probe targeting the chromodomains of Polycomb repressive complex 1. Nature Chem Biol. 2016; 12(3):180-187. [PubMed: 26807715]

33. Lingel A, Sendzik M, Huang Y, Shultz MD, Cantwell J, Dillon MP, Fu X, Fuller J, Gabriel T, Gu XJ, Jiang X, Li L, Liang F, McKenna MM, Qi W, Rao W, Sheng X, Shu W, Sutton J, Taft BR, Wang L, Zeng J, Zhang H, Zhang M, Zhao K, Lindvall MK, Bussiere DE. Structure-Guided Design of EED Binders Allosterically Inhibiting the Epigenetic Polycomb Repressive Complex 2 (PRC2) Methyltransferase. J Med Chem. 2016

34. Astle JM, Simpson LS, Huang Y, Reddy MM, Wilson R, Connell S, Wilson J, Kodadek T. Seamless bead to microarray screening: rapid identification of the highest affinity protein ligands from large combinatorial libraries. Chem Biol. 2010; 17(1):38-45. [PubMed: 20142039]

35. Lam KS, Salmon SE, Hersh EM, Hruby VJ, Kazmierski WM, Knapp RJ. A new type of synthetic peptide library for identifying ligand-binding activity. Nature. 1991; 354(6348):82-84. [PubMed: 1944576]

36. Doran TM, Gao Y, Mendes K, Dean S, Simanski S, Kodadek T. Utility of redundant combinatorial libraries in distinguishing high and low quality screening hits. ACS Comb Sci. 2014; 16(6):259270. [PubMed: 24749624]

37. Gao Y, Kodadek T. Synthesis and screening of stereochemically diverse combinatorial libraries of peptide tertiary amides. Chem Biol. 2013; 20(3):360-369. [PubMed: 23521794]

38. Gao Y, Amar S, Pahwa S, Fields G, Kodadek T. Rapid lead discovery through iterative screening of one bead one compound libraries. ACS Comb Sci. 2014; 17(1):49-59. [PubMed: 25434974]

39. Qi X, Astle J, Kodadek T. Rapid identification of orexin receptor binding ligands using cell-based screening accelerated with magnetic beads. Mol BioSyst. 2010; 6(1):102-107. [PubMed: 20024071] 
a)

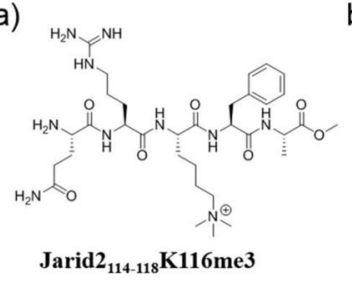

b)

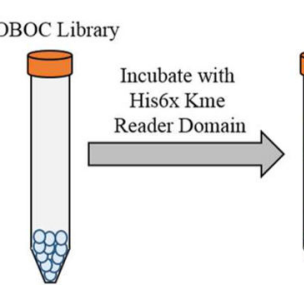

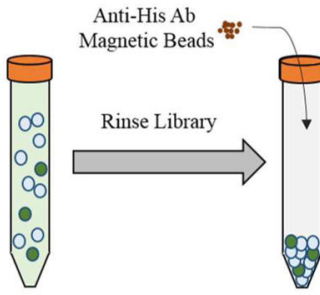

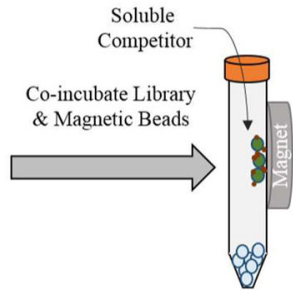

c)

$$
\text { (1) }
$$

Constan
Linker

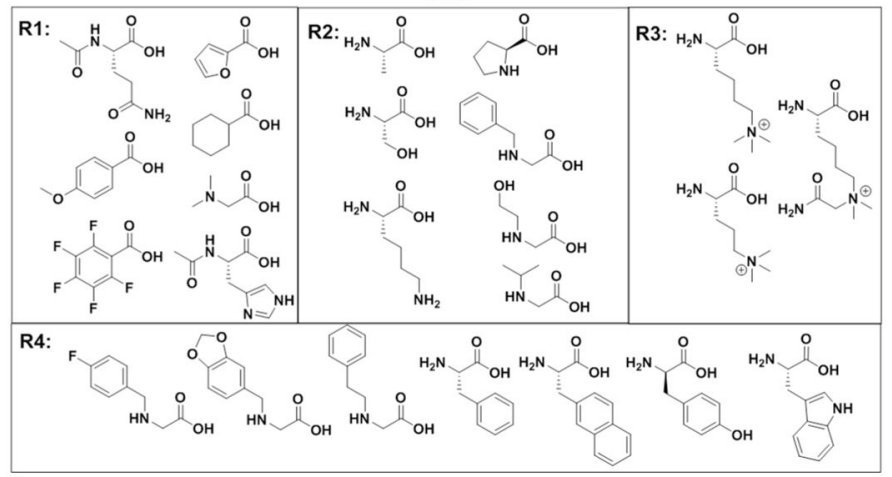

d)
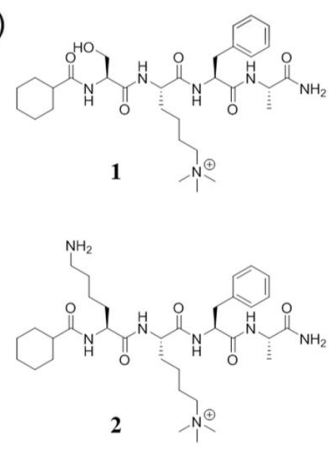

Figure 1.

(a) Structure of truncated Jarid2 peptide, Jarid $2114-118 \mathrm{~K} 116 \mathrm{me} 3$. This native ligand served as the scaffold for subsequent ligand optimization studies and soluble competitor for the first generation combinatorial library. (b) The library screening scheme is presented. The OBOC library is incubated with His-tagged Kme reader proteins, excess protein is removed by rinsing. Protein G Dynabeads coated in anti-His antibody then enable magnetic enrichment of hit compounds while subsequent treatment with a soluble competitor elutes off lower affinity hits. (c) Jarid $2{ }_{114-118} \mathrm{~K} 116 \mathrm{me} 3$-derivative library was designed to probe ligand requirements at positions $\mathrm{R} 1-\mathrm{R} 4$. The native Jarid2 sequence was retained as the linker while also including methionine to enable hit cleavage via $\mathrm{CNBr}$ treatment. (d) High redundancy EED ligands. Both analogs were enriched via the magnetic enrichment assay with greater than two-fold redundancy. 

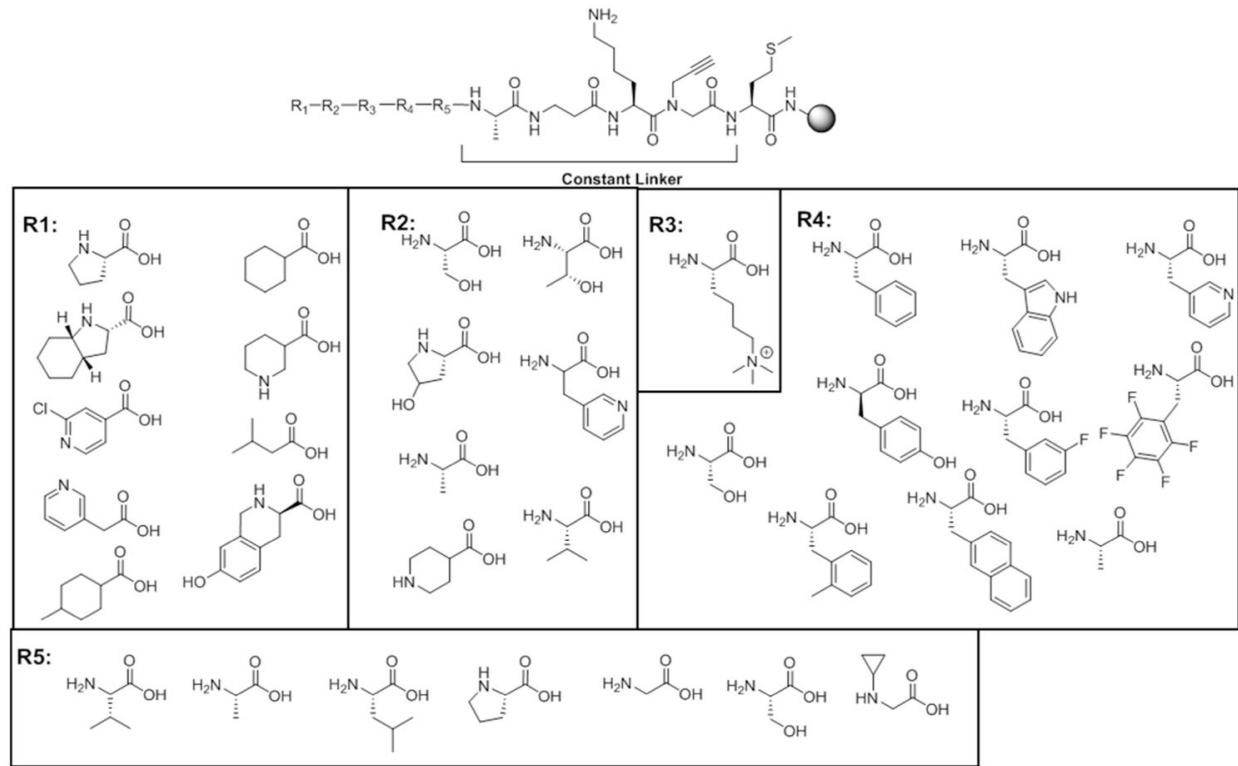

Figure 2.

Compound 1-derivative library was designed to improve EED ligand potency by exploring a narrower region of chemical space at R1-R4 while also probing the tolerance of the R5 position to modification. The linker sequence provides distance between the library sequence and the solid support, and methionine was required for hit cleavage. Additionally, a lysine was included in the linker to promote proper display of the compounds on the bead surface $^{39}$. 
a)
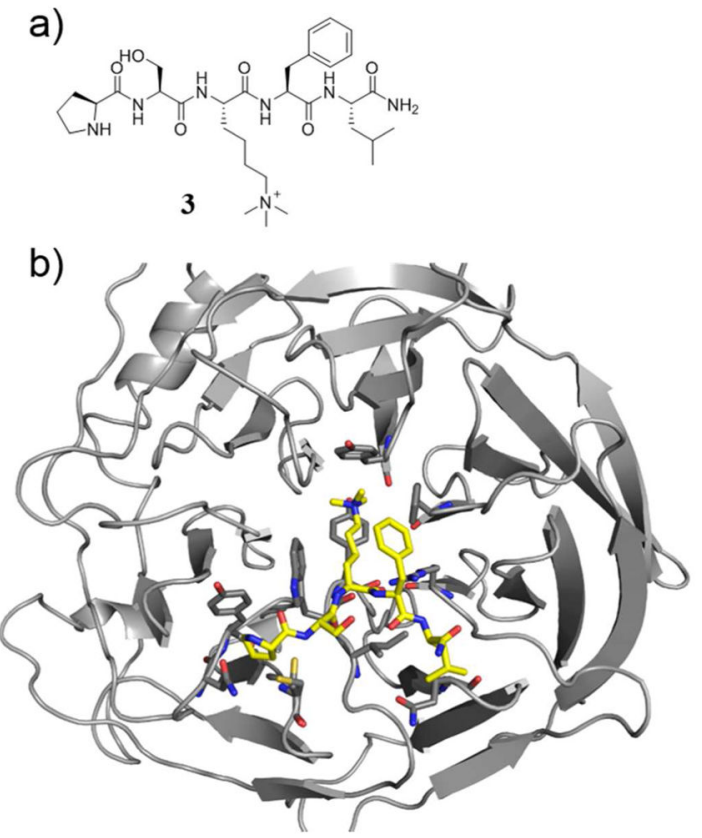

c)

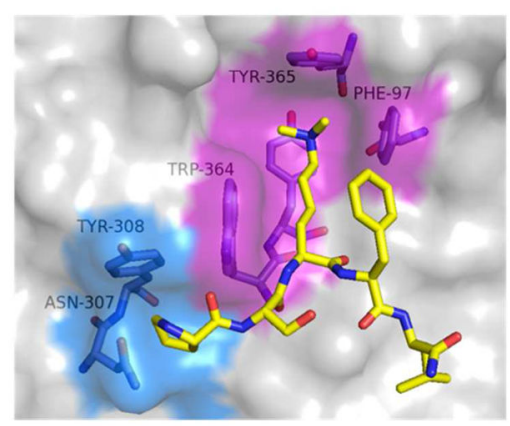

d)

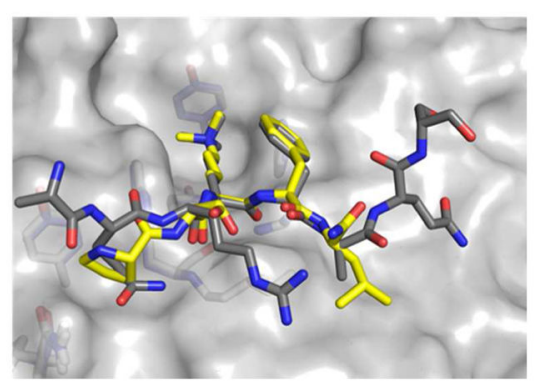

Figure 3.

a) Structure of compound $\mathbf{3}$. The sequence was derived from the residues found to occur most frequently at each position in the redundant hits of the second generation combinatorial library. b) Co-crystal structure of compound $\mathbf{3}$ bound to EED (PDB 5TTW). c) The aromatic cage (magenta) and the adjacent hydrophobic pocket (blue) occupied by Kme3 and proline, respectively. The backbone of the serine residue bridges these two pockets while the side chain points to solvent. d) Alignment of Jarid2 $110-120^{-K} 116 \mathrm{me} 3$ (dark grey) and compound 3 (yellow) structures bound to EED demonstrating the constrained proline ring (compound 3) replaces glutamine (Jarid2 $110-120-\mathrm{K} 116 \mathrm{me} 3$ ) and leucine (compound 3 ) contacts a broader surface than alanine (Jarid2 $\left.110-120^{-K} 116 \mathrm{me} 3\right)$. 
a)

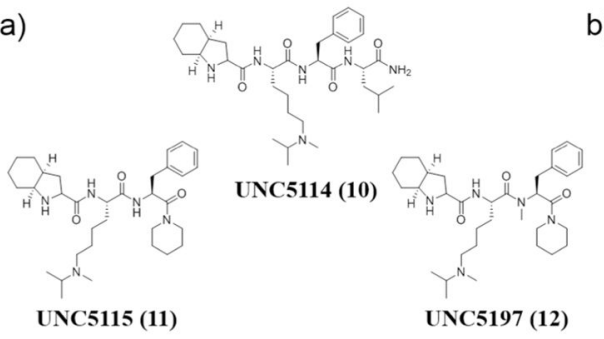

b)

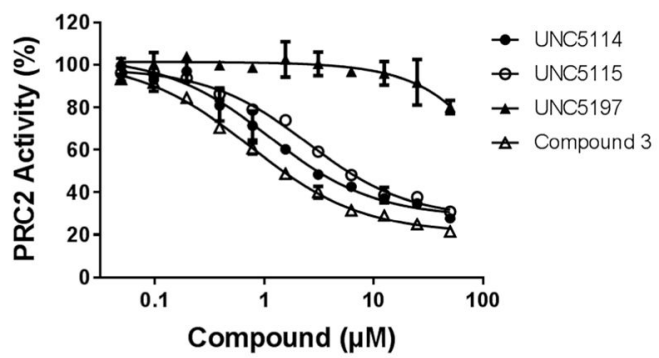

Figure 4.

a) Structures of UNC5114, UNC5115, and UNC5197. b) In vitro PRC2 catalytic scintillation proximity assay results for highest potency EED binders and the negative control demonstrate this series of ligands inhibits PRC2 methyltransferase activity. 
a)

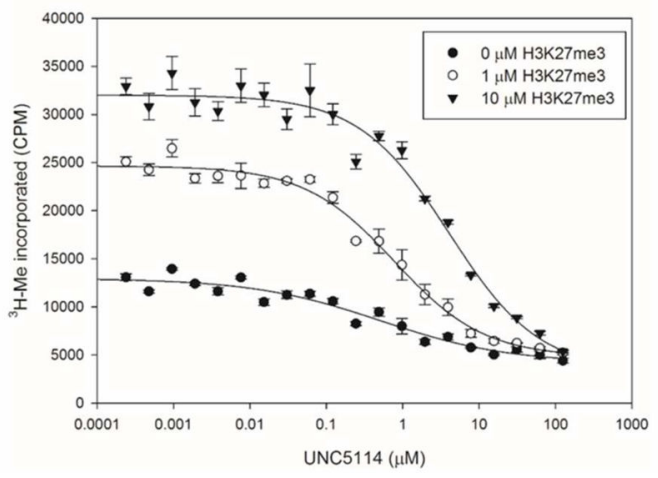

c)

\begin{tabular}{ccc}
\hline H3K27me3 $(\boldsymbol{\mu M})$ & IC50 $(\boldsymbol{\mu M})$ & Hill Slope \\
\hline 0 & $0.5 \pm 0.3$ & $0.5 \pm 0.1$ \\
1 & $0.8 \pm 0.1$ & $0.73 \pm 0.09$ \\
10 & $4 \pm 1$ & $0.7 \pm 0.1$ \\
\hline
\end{tabular}

b)

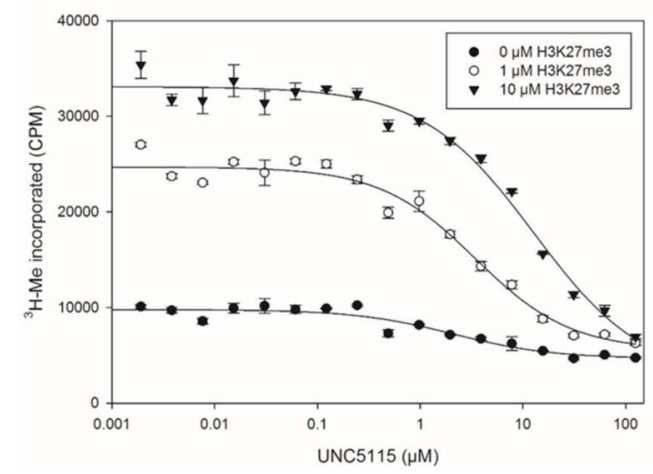

d)

\begin{tabular}{ccc}
\hline H3K27me3 $(\mu \mathrm{M})$ & IC50 $(\mu \mathrm{M})$ & Hill Slope \\
\hline 0 & $2.1 \pm 0.9$ & $0.9 \pm 0.3$ \\
1 & $3.4 \pm 0.8$ & $0.9 \pm 0.2$ \\
10 & $13 \pm 4$ & $0.8 \pm 0.1$ \\
\hline
\end{tabular}

Figure 5.

Effect of H3K27me3 competition at varying concentrations on a) UNC5114, and b) UNC5115 inhibition of PRC2 catalytic activity. $\mathrm{IC}_{50}$ and Hill slope values for c) UNC5114 and d) UNC5115. Experiments were carried out in triplicate. 
a)

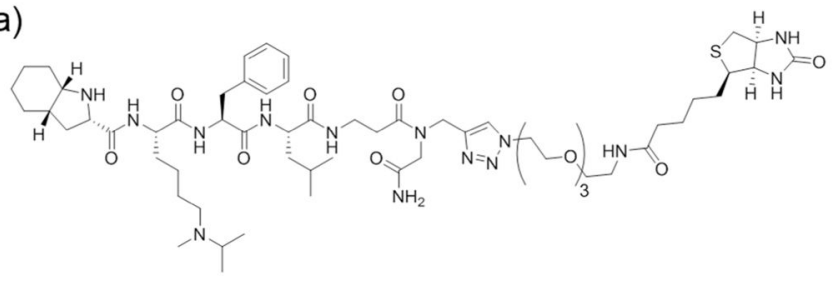

b) UNC5114-

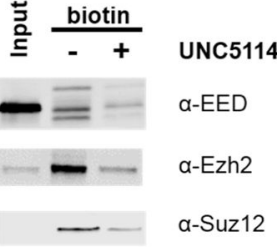

Figure 6.

Chemiprecipitation of PRC2 core proteins. (A) Structure of C-terminally biotinylated derivative of UNC5114. (B) Western blot analysis indicating that UNC5114-biotin chemiprecipitates the intact PRC2 complex from PC-3 lystates with isolation of EED, Ezh2, and Suz12 (-). In the presence of soluble UNC5114, the ability of UNC5114-biotin to chemiprecipitate PRC2 is significantly reduced $(+)$. 

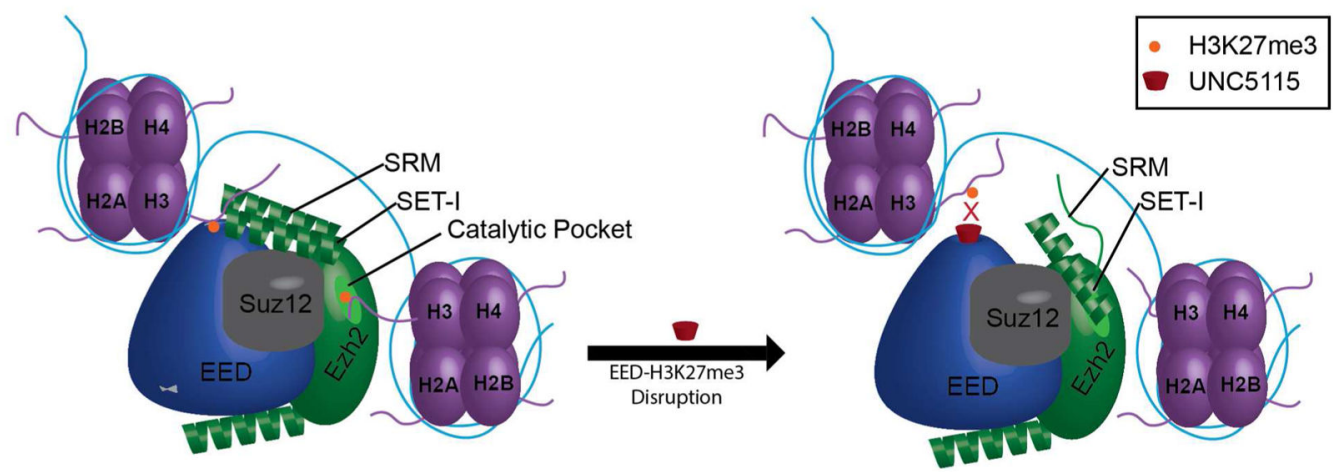

Figure 7.

Model for allosteric inhibition of PRC2 catalytic activity. EED aromatic cage ligands prevent binding of activating H3K27me3 peptides and may disrupt the stabilization of the SRM helix which in turn fails to engage and stabilize the SET-I helix. 


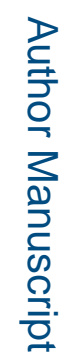

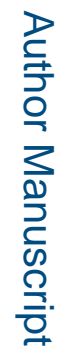

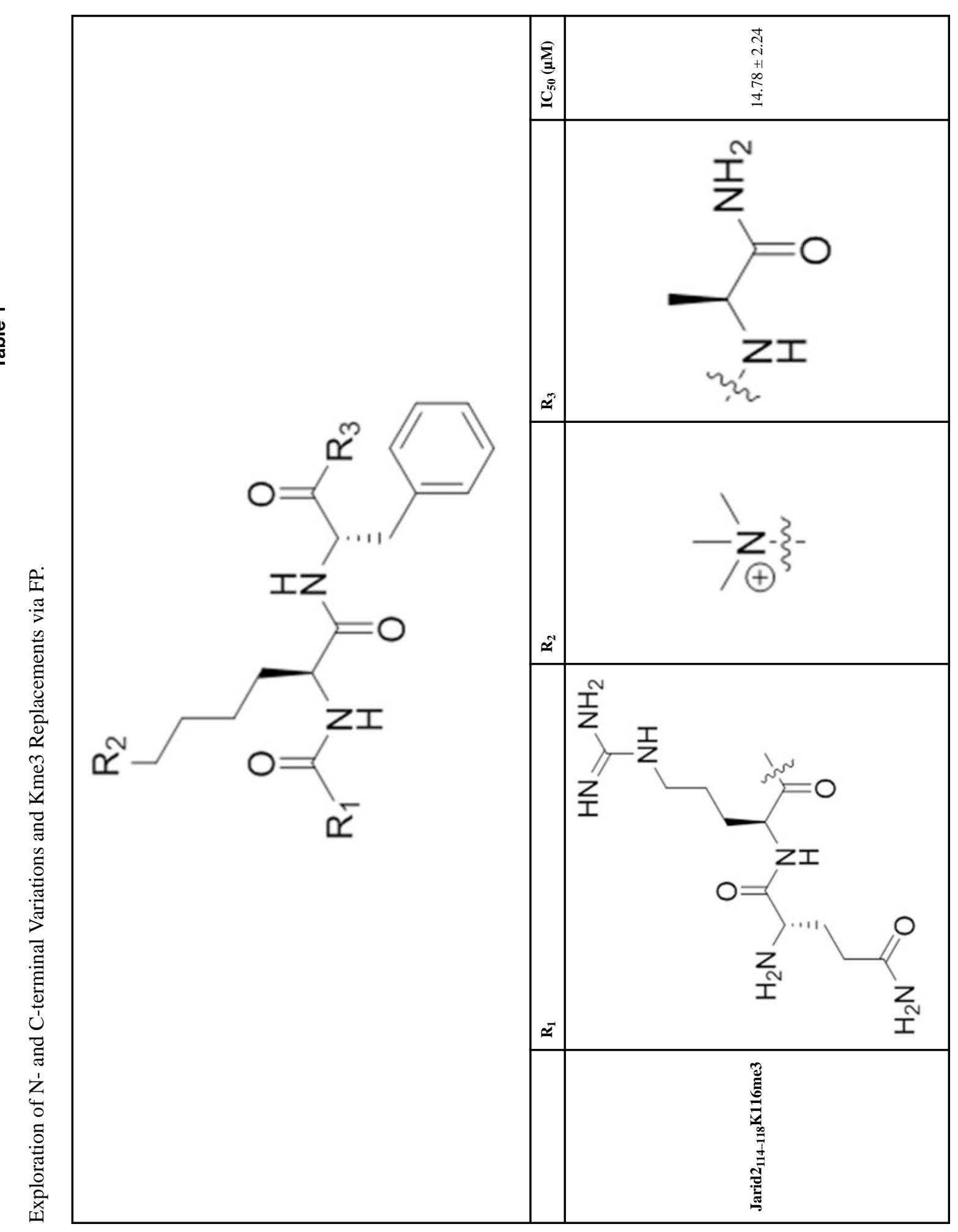

ACS Comb Sci. Author manuscript; available in PMC 2018 March 13. 


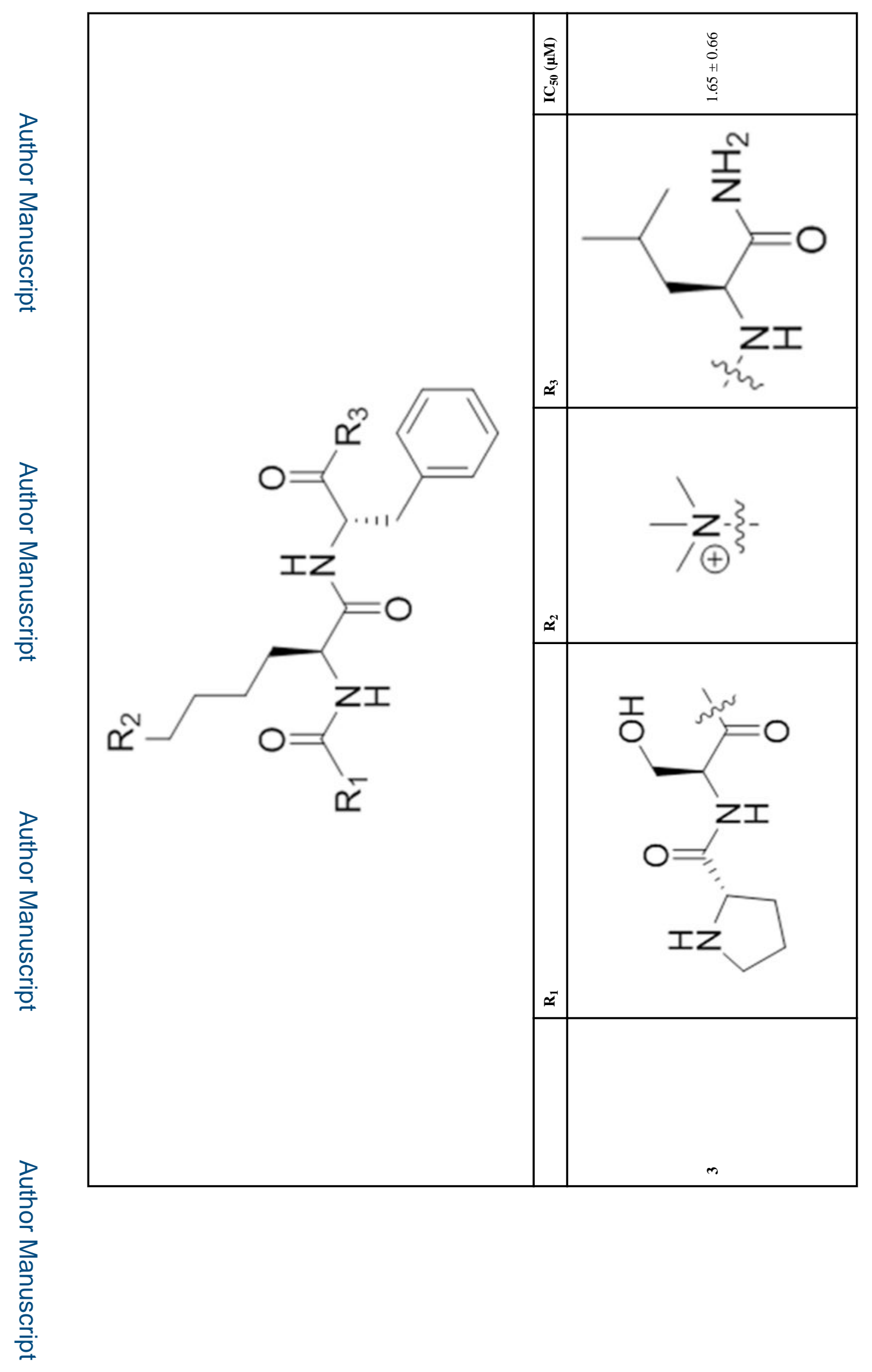




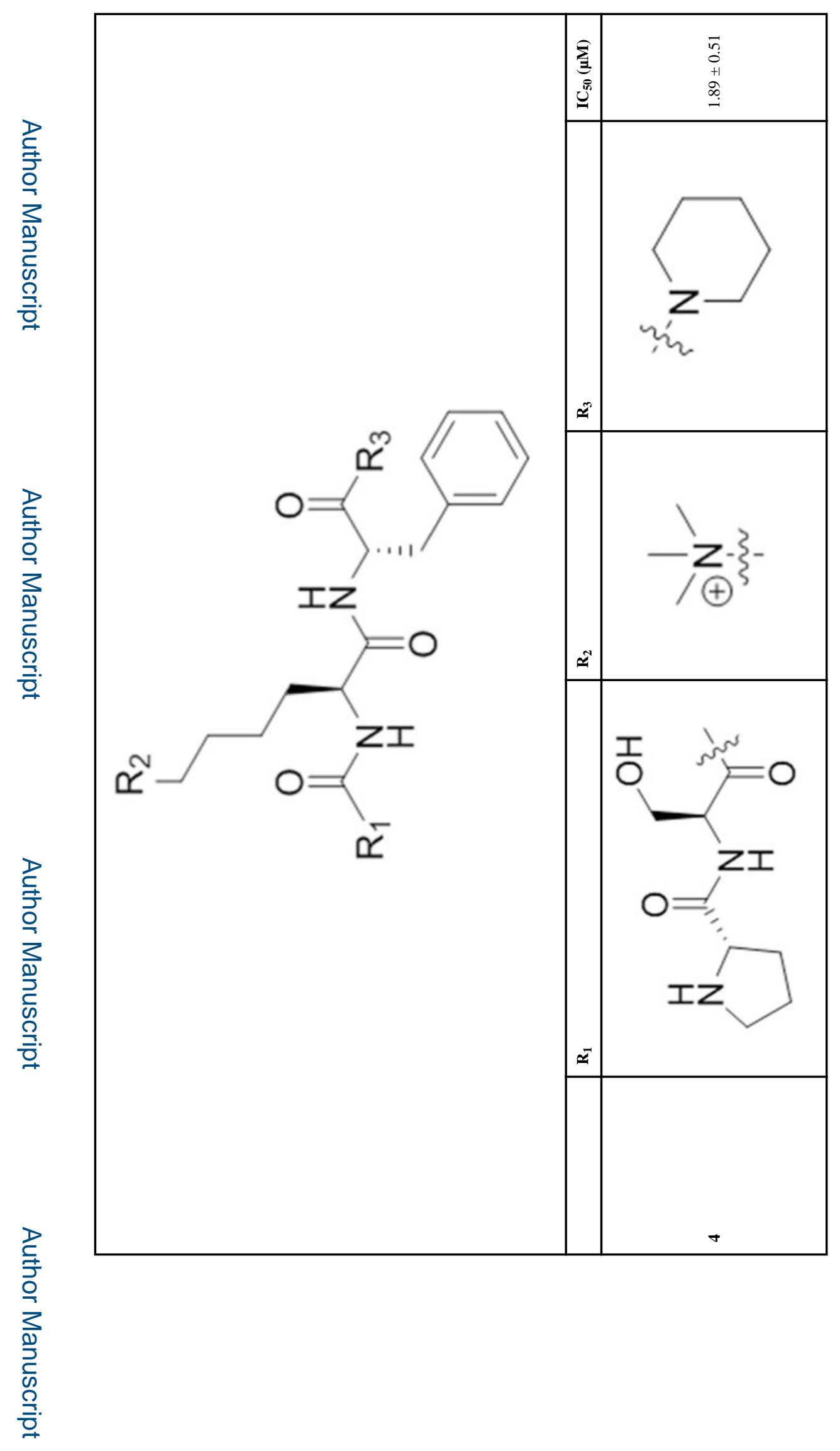




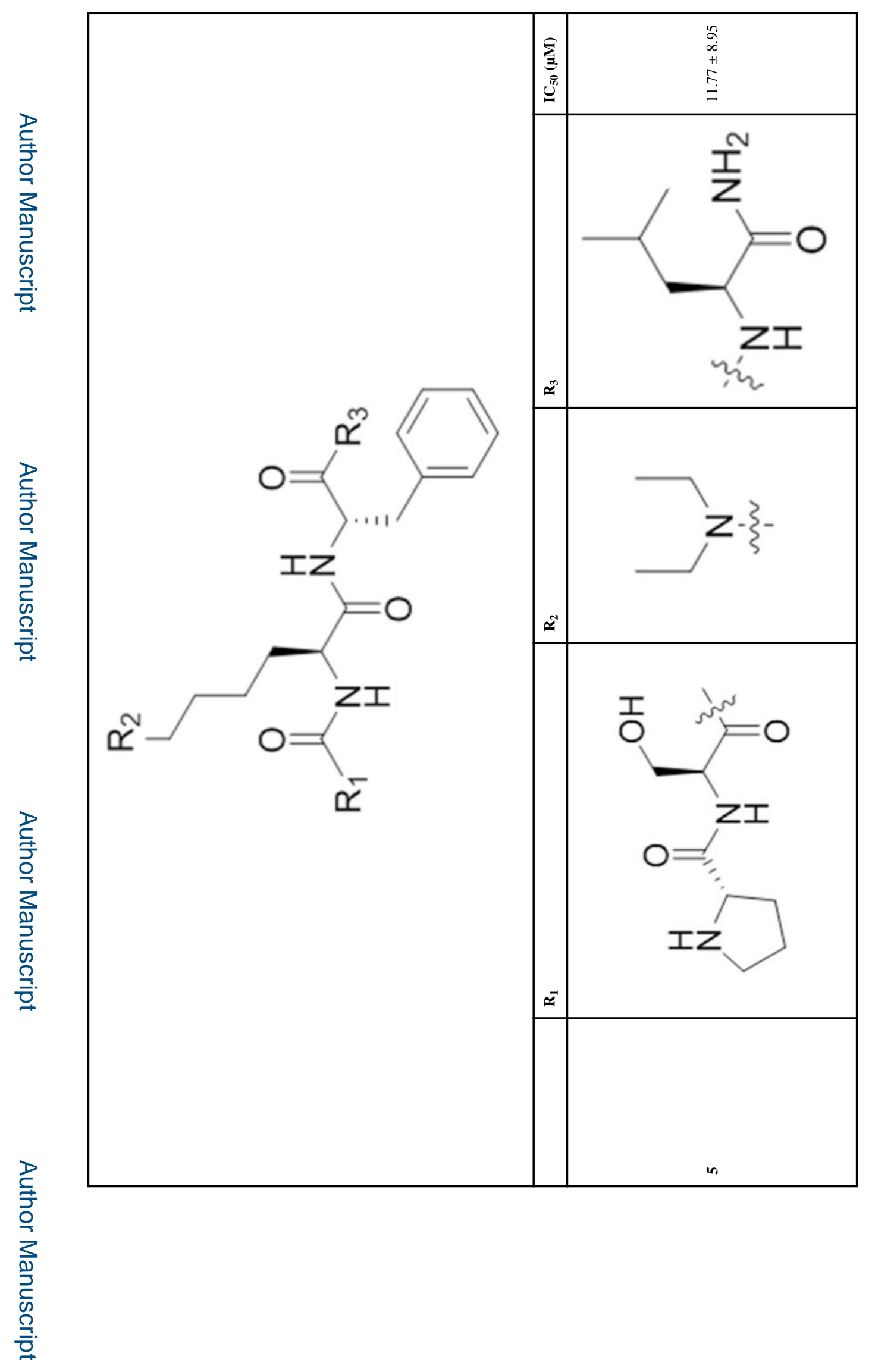




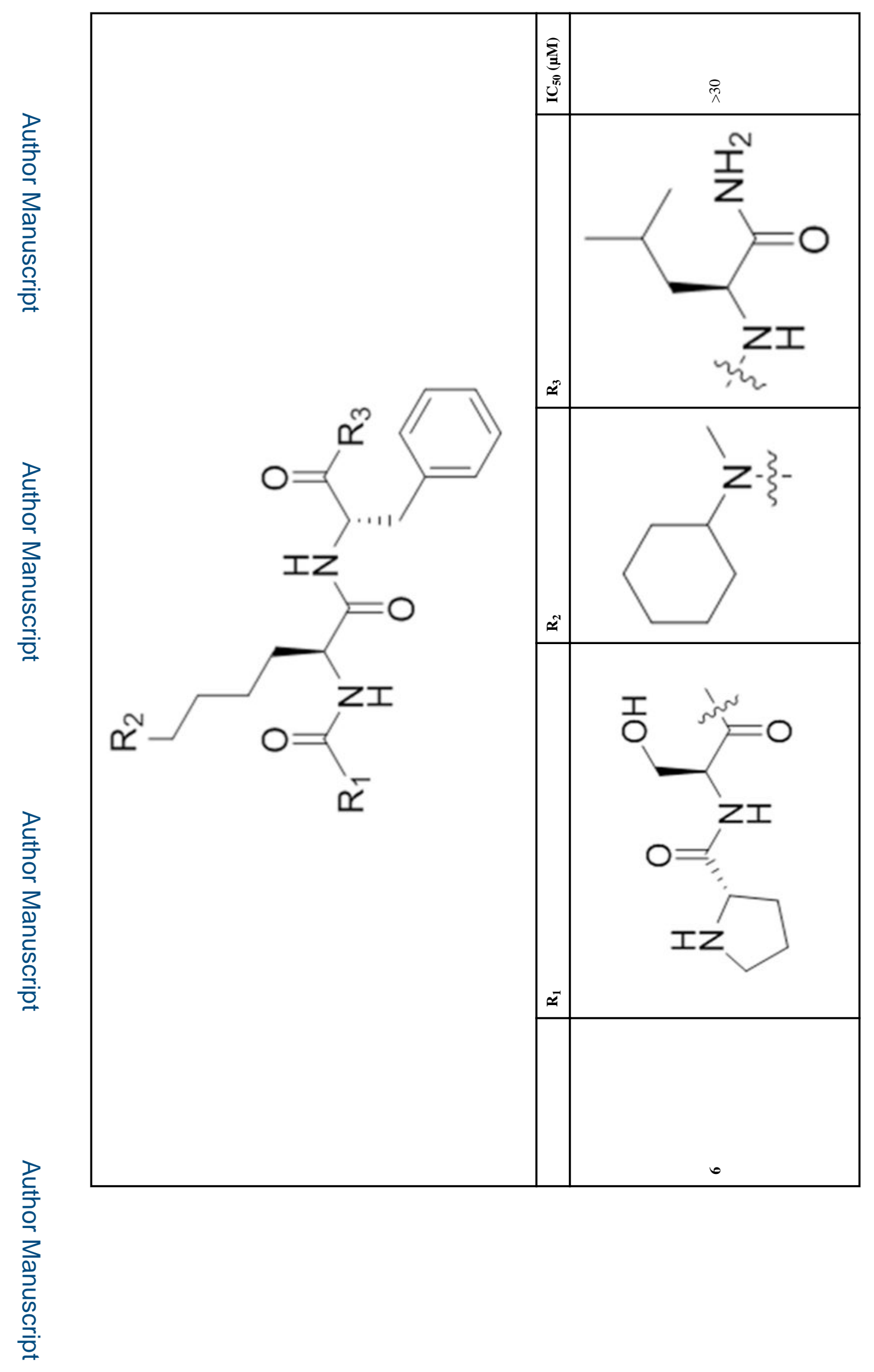




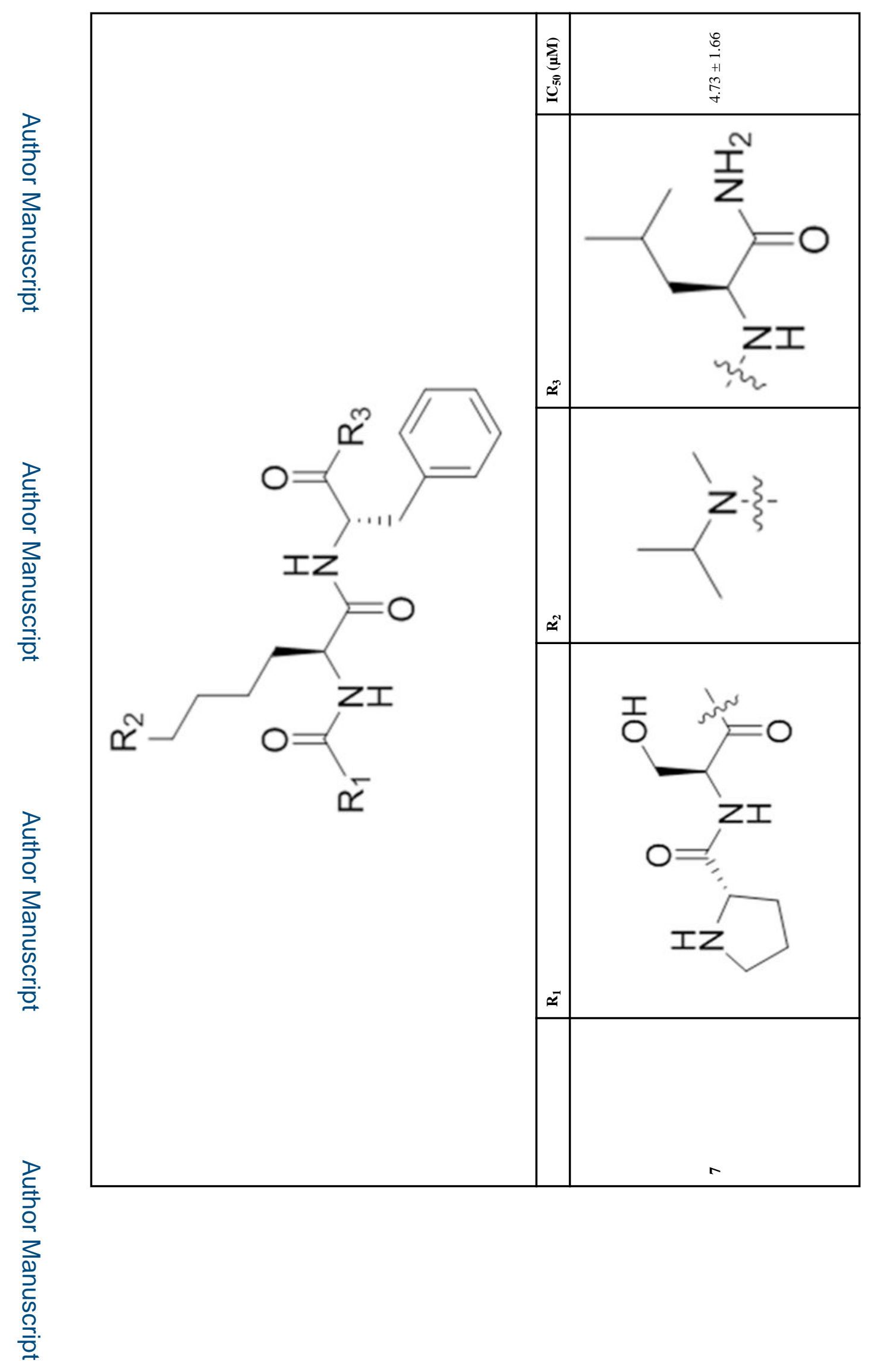




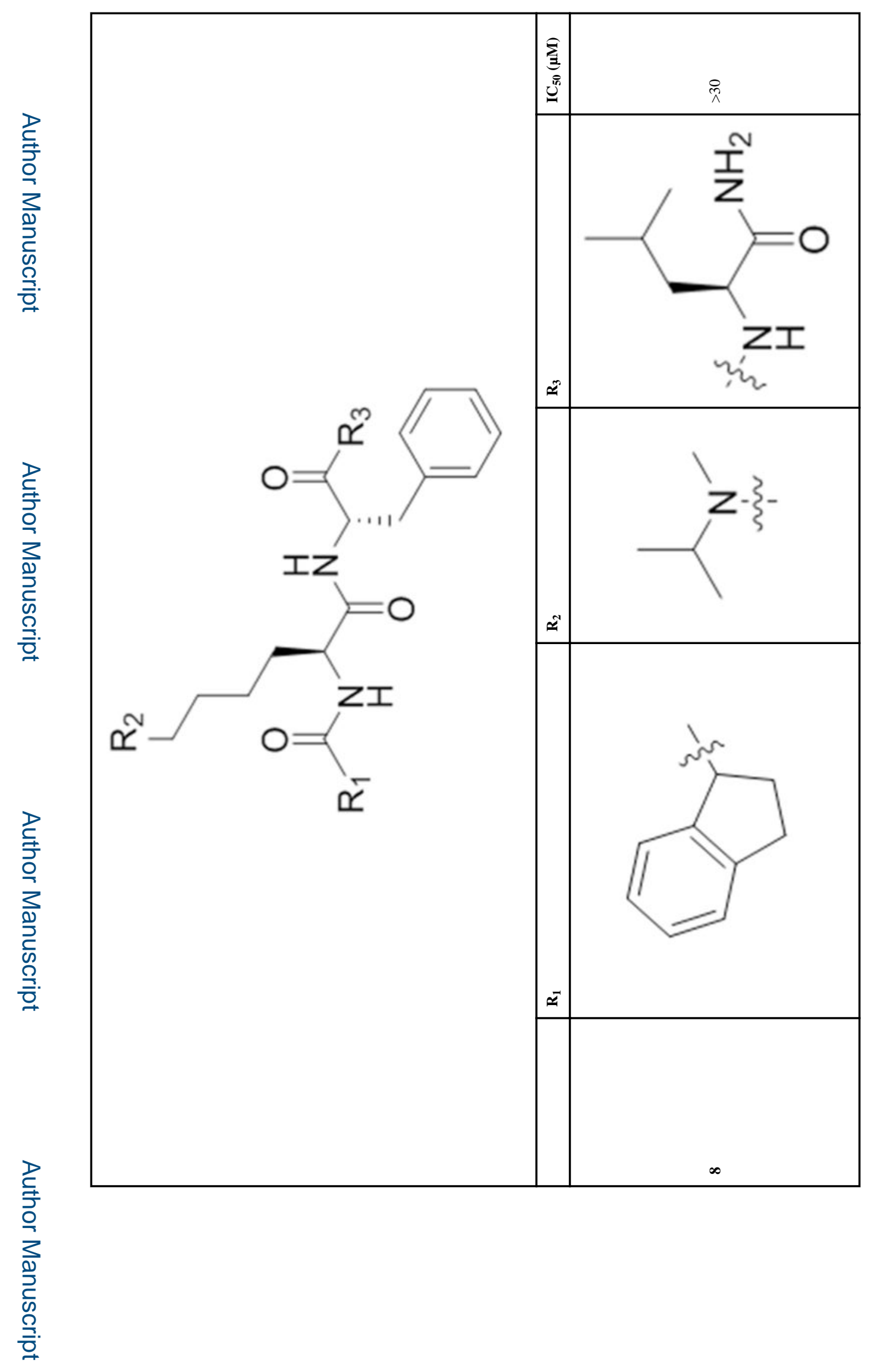




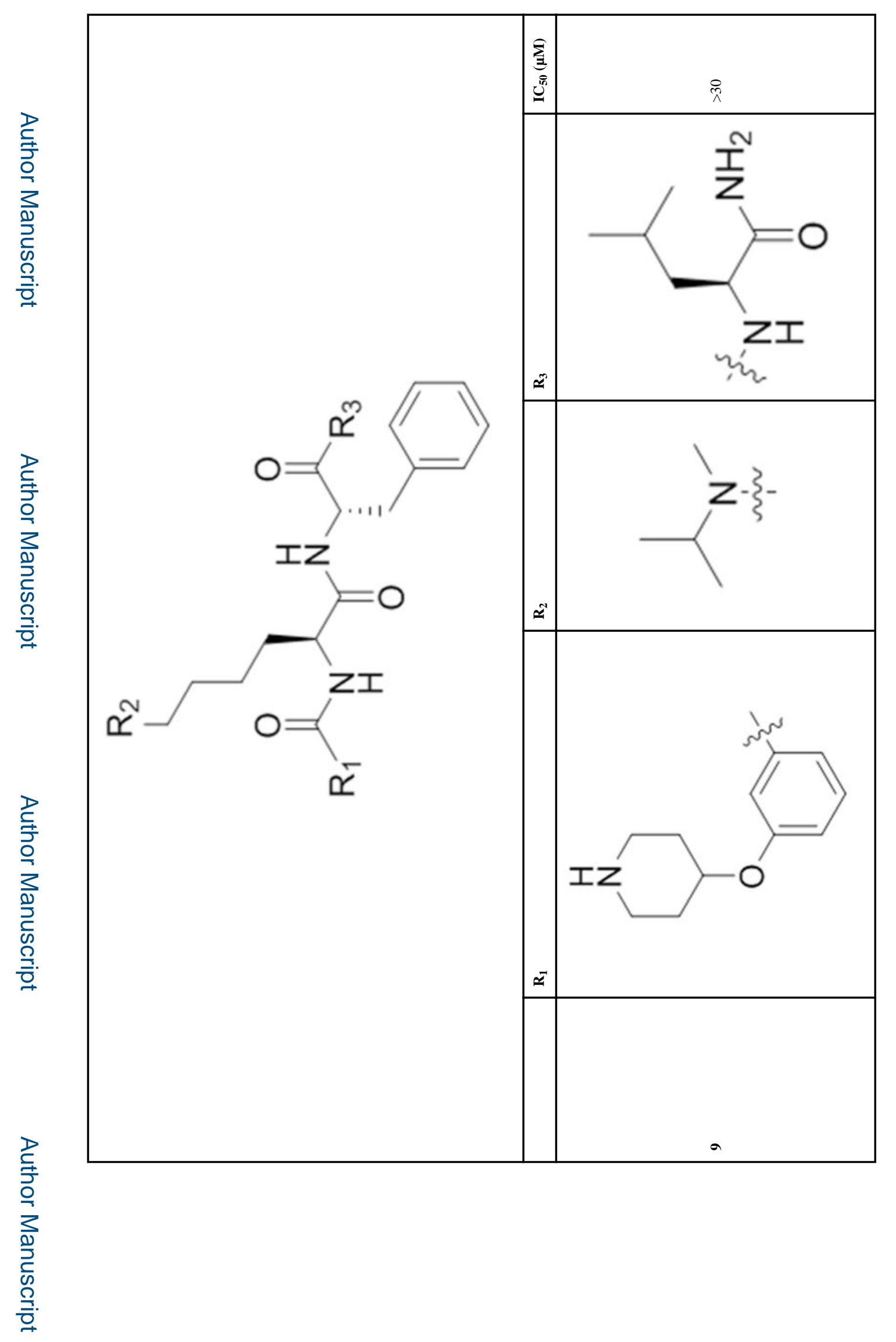




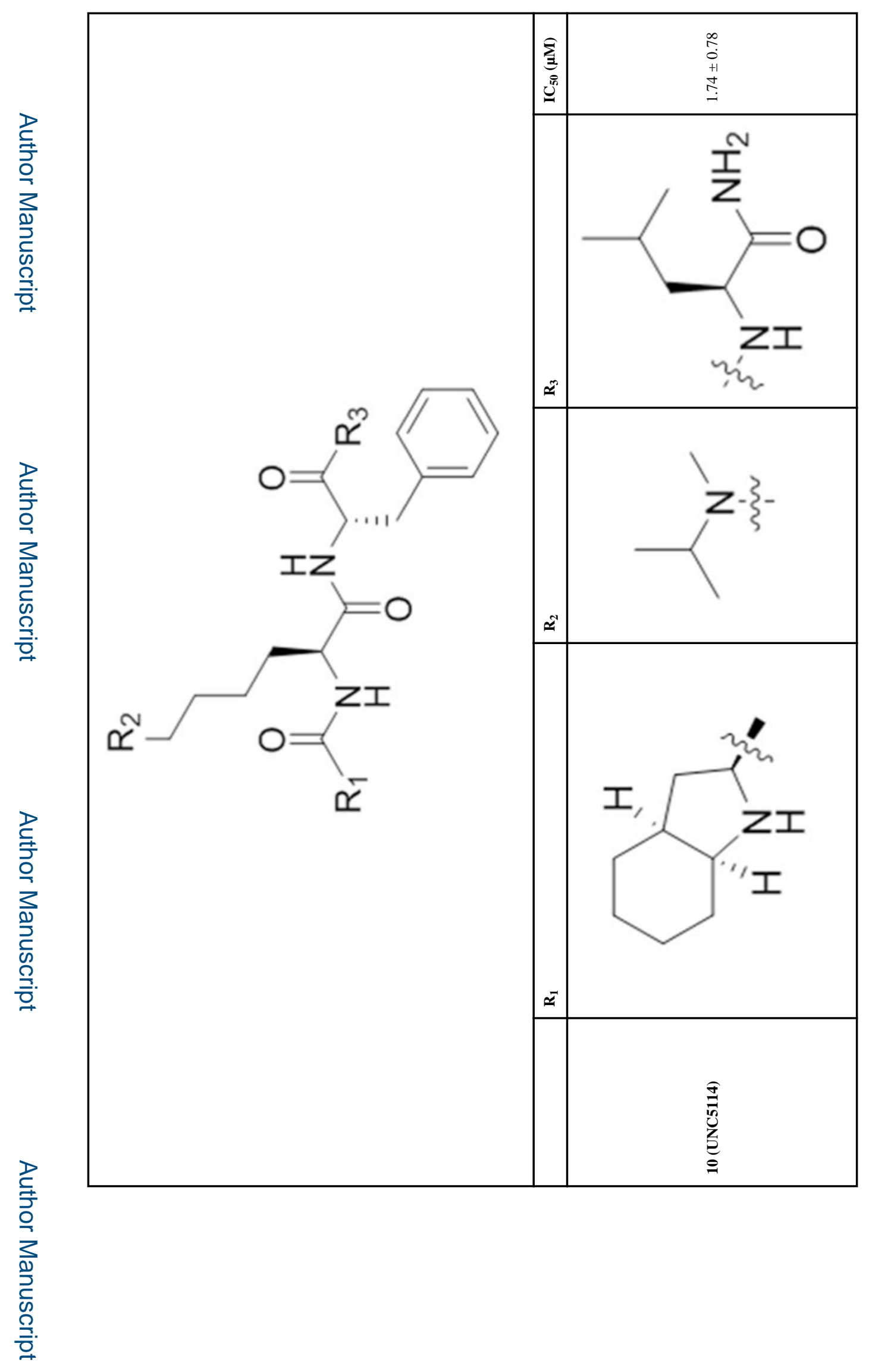




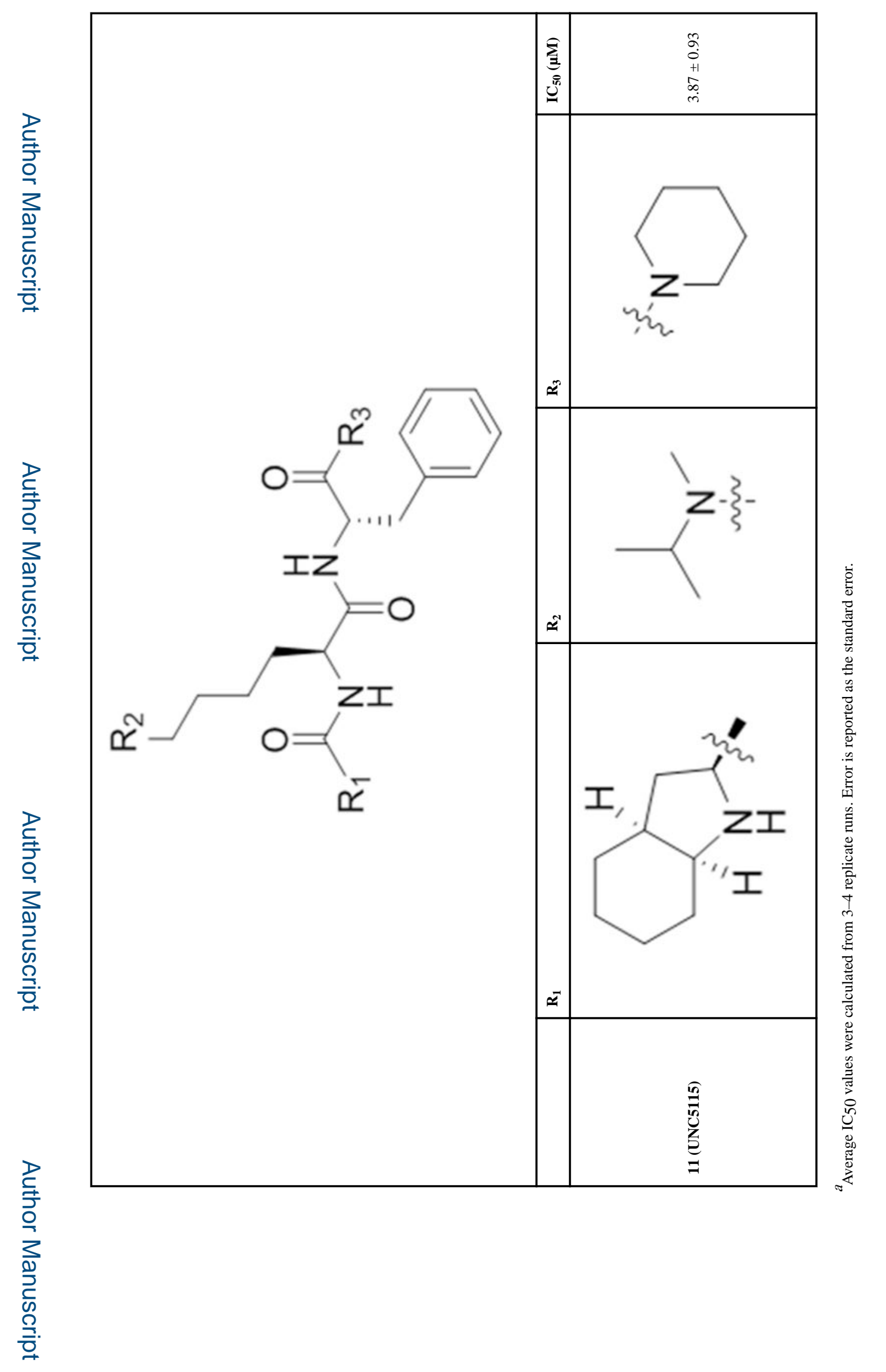

